\title{
Candida Biofilms and the Host: Models and New Concepts for Eradication
}

\author{
Hélène Tournu ${ }^{1,2}$ and Patrick Van Dijck ${ }^{1,2}$ \\ ${ }^{1}$ Laboratory of Molecular Cell Biology, Institute of Botany and Microbiology, Katholieke Universiteit Leuven, \\ Flanders, 3001 Leuven-Heverlee, Belgium \\ ${ }^{2}$ Department of Molecular Microbiology, VIB, Kasteelpark Arenberg 31, Flanders, 3001, Leuven-Heverlee, Belgium
}

Correspondence should be addressed to Hélène Tournu, helene.tournu@mmbio.vib-kuleuven.be

Received 7 August 2011; Accepted 30 September 2011

Academic Editor: Arianna Tavanti

Copyright (C 2012 H. Tournu and P. Van Dijck. This is an open access article distributed under the Creative Commons Attribution License, which permits unrestricted use, distribution, and reproduction in any medium, provided the original work is properly cited.

Biofilms define mono- or multispecies communities embedded in a self-produced protective matrix, which is strongly attached to surfaces. They often are considered a general threat not only in industry but also in medicine. They constitute a permanent source of contamination, and they can disturb the proper usage of the material onto which they develop. This paper relates to some of the most recent approaches that have been elaborated to eradicate Candida biofilms, based on the vast effort put in ever-improving models of biofilm formation in vitro and in vivo, including novel flow systems, high-throughput techniques and mucosal models. Mixed biofilms, sustaining antagonist or beneficial cooperation between species, and their interplay with the host immune system are also prevalent topics. Alternative strategies against biofilms include the lock therapy and immunotherapy approaches, and material coating and improvements. The host-biofilm interactions are also discussed, together with their potential applications in Candida biofilm elimination.

\section{Introduction}

Biofilms, adherent microbial communities embedded in a polymer matrix, are common in nature. However, they are also a persistent cause of hygiene problems in the food industry and in the medical field [1]. Biofilms result from a natural tendency of microbes to attach to biotic or abiotic surfaces, which can vary from mineral surfaces and mammalian tissues to synthetic polymers and indwelling medical devices, and to further grow on these substrates [2-4]. Candidiasis, caused most frequently by Candida albicans, and to a lesser extent by C. glabrata, C. tropicalis, or C. parapsilosis, is often associated with the formation of biofilms on the surface of medical devices and tissues [5]. Candida albicans is a dimorphic fungus and is part of the commensal human micoflora. It is also an opportunistic pathogen of the human body when its proliferation is not controlled by the host immune system. It is one of the most often identified agents in nosocomial infections and is capable of invading virtually any site of the human host, from deep tissues and organs, to superficial sites such as skin and nails, to medical implants and catheters [6]. C. albicans biofilm development has been characterized in various model systems both in vitro and in vivo [7-9] and consists of distinct phases. The initial step consists of the adhesion of fungal cells of the yeast form to the substrate. It is followed by a phase of cell filamentation and proliferation, which results in the formation of multiple layers of sessile cells of different morphologies, including pseudohyphal and hyphal cells. The next step of maturation results in a complex network of cells embedded in extracellular polymeric material, composed of carbohydrates, proteins, hexosamine, phosphorus and uronic acid, as well as host constituents in natural settings [10]. There is indeed evidence that host glycoproteins, nucleic acids, and cells, such as neutrophils, may participate in the maturity of the matrix, in particular on mucosal sites [11-13]. The establishment of the biofilm extracellular matrix (ECM) represents a unique characteristic of biofilms. Quantity and composition of the matrix vary from one species to another and in different sites of infection depending on environmental cues, 
TABle 1: Examples of Candida biofilm models in vitro.

\begin{tabular}{|c|c|c|}
\hline Models in vitro & Device & Used for \\
\hline \multirow{3}{*}{$\begin{array}{l}\text { Closed systems (discontinuous growth } \\
\text { conditions over time (nutrient depletion, } \\
\text { accumulation of secondary metabolites)) }\end{array}$} & $\begin{array}{l}\text { (i) 96-well polystyrene microtiter plate } \\
\text { (ii) Discs/pieces of catheter in 6- to } \\
\text { 24-well plate (discs made of silicone, } \\
\text { polyurethane, polycarbonate, polystyrene, } \\
\text { stainless steel, Teflon, polyvinyl chloride, } \\
\text { hydroxyapatite, and porcelain) }\end{array}$ & $\begin{array}{l}\text { Easy and widespread use: comparative analyses } \\
\text { between strains and species [33-39] to antifungal } \\
\text { susceptibility tests [40] }\end{array}$ \\
\hline & $\begin{array}{l}\text { (iii) Calgary biofilm device ( } 80 \text { pegs } \\
\text { immersed into a standard } 96 \text {-well plate) }\end{array}$ & $\begin{array}{l}\text { Biofilm formation studies by different Candida } \\
\text { species [41] }\end{array}$ \\
\hline & $\begin{array}{l}\text { (iv) Candida biofilm chip (several } \\
\text { hundreds nanobiofilms encapsulated in } \\
\text { collagen and formed on a glass slide } \\
\text { treated to obtained a monolayer of } \\
\text { hydrophobic coating) }\end{array}$ & High-throughput biofilm studies [42] \\
\hline \multirow{4}{*}{$\begin{array}{l}\text { Flow systems (Continuous growth } \\
\text { conditions) }\end{array}$} & $\begin{array}{l}\text { (i) CDC biofilm reactor ( } 24 \text { biofilms can } \\
\text { be formed simultaneously) }\end{array}$ & $\begin{array}{l}\text { Comparative analysis of biofilm quantification } \\
\text { methods [43] }\end{array}$ \\
\hline & $\begin{array}{l}\text { (ii) Microfermentors (biofilms formed on } \\
\text { a Thermanox slide glued to a glass spatula) }\end{array}$ & Gene expression analyses [44] \\
\hline & $\begin{array}{l}\text { (iii) Modified Robbins device (adapted to } \\
\text { hold several individual discs) }\end{array}$ & $\begin{array}{l}\text { Study of the effects of shear forces and nutrient } \\
\text { supplies on C. albicans biofilm formation [45] }\end{array}$ \\
\hline & $\begin{array}{l}\text { (iv) Flow biofilm model (silicone } \\
\text { elastomer strip placed into a } \\
\text { polypropylene conical tube) }\end{array}$ & $\begin{array}{l}\text { Study of C. albicans biofilm development, } \\
\text { architecture, and drug resistance [46] }\end{array}$ \\
\hline Shear stress conditions & $\begin{array}{l}\text { Rotating disc system ( silicone catheter } \\
\text { devices placed under a shear force of } 350 \\
\text { revolutions per minute) }\end{array}$ & $\begin{array}{l}\text { C. albicans biofilm architecture and development } \\
\text { [47] }\end{array}$ \\
\hline
\end{tabular}

such as nutrient availability and mechanical stimuli [1417]. Matrix synthesis by Candida biofilm cells has been shown to be minimal in static conditions in comparison to dynamic environments [10], aggravating biofilm formation on mucosal and abiotic sites where there is a fluid flow, such as on the oral mucosa, the urethra, or central venous catheters. The last step, dispersion of cells from a biofilm, plays a key part in the biofilm developmental cycle as it is associated with candidemia and disseminated invasive disease [18].

Pathogenic microbes that build biofilms are potential causes of constant infections that defy the immune system and resist antimicrobial treatment, partly due to the matrixinherent limited exposure of the cells within a biofilm to these types of immunological and medical arsenals [1922]. Other mechanisms of biofilm resistance have been suggested, such as slow growth, differential regulation of the cell metabolic activity caused by nutrient limitation and stress conditions, and cell density [23-25]. In addition, the ability to adhere, as a unique prerequisite to form a biofilm, is a fast process, which makes the prevention of biofilm development difficult with the current antimicrobial tools and strategies.

Biofilms are diverse communities and therefore vary depending on the microbe, the surface, and the colonization niche $[5,26-30]$. This paper gives an update on the recent efforts made in establishing alternative means of eradication and also prevention of Candida spp. biofilms, by developing new models of biofilm formation in flow conditions, as well as high-throughput rapid screening analyses in vitro. Newly developed in vivo models anticipate a shift of interest towards mixed fungal-bacterial biofilms and their role in pathogenesis in mucosal infections in particular. Keeping in mind that there is no unique model representative of all biofilms, it remains quite a challenge to tackle biofilm inhibition. One of the most attractive perspectives is the development of antimicrobe materials, and the latest findings are presented here.

\section{Candida Biofilm Models}

2.1. Models In Vitro. Biofilm formation is a multistep growth behaviour that results from complex physical, chemical, and biological processes $[31,32]$. Because of the versatility of the milieu in which Candida biofilms can develop in the human host, from the oral cavity contributing to dental plaque formation to the blood stream in intravenous catheters and the urinary tract, it seemed necessary to reproduce in vitro as many conditions as possible to establish common and specific characteristics of Candida biofilm formation. In that respect, a multitude of in vitro studies has been described that relates to the impact of different types of substrate, nutritional supplies, in flow or static conditions, on adhesion and biofilm properties of several Candida species, and recent findings are presented next. An overview of the in vitro models available to study Candida biofilms is provided in Table 1 . 
2.1.1. Candida Species and Substrates Specificities. While biofilm formation is a general characteristic of many microbes, biofilm features such as architecture, matrix composition, and resistance to antifungal drugs are species and substrate dependent. And examples that demonstrate variation in biofilm ability and structure are numerous. Some studies are discussed below, and in particular studies related to Candida biofilms formed on dental materials. Interest has indeed grown in investigating the role of Candida species and the effect of the type of material in the development of denture stomatitis [48]. For example, in a comparative study, cell counts analyses showed that saliva-coated discs harboured less C. glabrata cells than untreated discs, while the number of $C$. albicans cells was not affected by the saliva coating [33]. However, both species adhered better on hydroxyapatite (HA) surface than on two other types of dental material, polymethylmetacrylate and soft denture liner. Surprisingly, dual species experiments showed that $C$. glabrata displayed higher cell counts when grown in the presence of $C$. albicans than when grown alone. In contrast, hyphal development by C. albicans seemed to be reduced in the presence of C. glabrata in most of the conditions tested. These data may help understand the impact that Candida species may have on each other, as mixed species communities are being identified in clinical samples [49]. In another case study, using discs as support for biofilm formation in vitro, HA substrate appeared to be less prone to Candida adherence than acrylic denture, porcelain, or polystyrene when not coated with saliva [34]. In addition, the effect of serum and similar materials on biofilm development of C. albicans clinical isolates was also evaluated in vitro [35]. Disc coupons made of polycarbonate, polystyrene, stainless steel, polytetrafluoroethylene (also known as Teflon), polyvinyl chloride (PVC), or HA were used in a high throughput assay. For all surfaces tested, the presence of serum increased biofilm formation. However, in absence of serum, Teflon supported higher biofilm production than any other material, likely due to its high roughness and hydrophobicity properties.

The differential ability to form biofilm of 84 strains from several Candida species, including C. albicans, C. glabrata, C. krusei, C. tropicalis, and C. parapsilosis, was assessed on clinical materials, such as Teflon and PVC. All species, with the exception of Candida glabrata, favoured Teflon [50]. In this study, C. glabrata together with C. krusei strains were not highly proficient in forming dense biofilms, as quantified by colony-forming units. Moreover, C. parapsilosis strains showed the least uniformity in the ability to form biofilm, followed by C. tropicalis and C. albicans. While some variability in the ability to form biofilms between strains of C. albicans has been documented in vitro, a study by MacCallum et al. [51] revealed that biofilm formation in vitro did not significantly vary between strains of the four major clades of $C$. albicans, classified according to singlenucleotide polymorphisms determinations and analysis of DNA repeat sequences [52]. However, high variation in the ability to form biofilm among strains of $C$. parapsilosis and less extensive biofilm formation by C. glabrata specimens has been illustrated in a few studies by crystal violet staining and confocal laser scanning microscopy [36-38]. Straindependent variation in biofilm formation was also observed among isolates of two genetically nonidentical classes of C. parapsilosis, namely, C. orthopsilosis and C. metapsilosis $[39,53]$. All three species could form biofilms, but metabolic activity of biofilm cells differed between strains of the same species. However, conflicting data with different isolates reported the inability of C. orthopsilosis and C. metapsilosis to form biofilm in polystyrene 96-well plate assay in vitro [54, 55]. Biofilm formation among C. parapsilosis sensu strictu strains was also found to vary according to the geographical regions and the body sites from which the isolates came from [56]. Isolates from blood and cerebrospinal fluid seemed more prone to form biofilms than isolates from nails, catheters, and mucosa. Overall, these data suggest a high variability in biofilm ability of strains of $C$. parapsilosis and related species, perhaps due to inadequate models or to an intrinsic poor ability to establish the biofilm growth by these species.

In a Calgary biofilm model adapted to Candida spp., $C$. krusei developed the largest biofilm mass in comparison to $C$. albicans, C. glabrata, C. dubliensis, and C. tropicalis [41]. This model, allowing 80 biofilms to be formed at once, seemed to be very favourable to C. krusei biofilm development as biofilms of that species constituted of thick multilayered structures composed of pseudohyphal cells, while the other species formed sparse biofilms.

In a last example of novel in vitro models of biofilm formation on various soft contact lenses, analyses revealed differences in hyphal content and architecture of the fungal keratitis causative agents Fusarium and C. albicans [57]. Polymers such as balafilcon A and galyfilcon A were favourable to filamentous growth of $C$. albicans, while others such as etafilcon A and lotrafilcon A sustained biofilms formed mainly of yeast cells. In addition, differences in biofilm formation were also observed between peripheral and central regions of the lenses, with dense biofilms formed preferentially in the centres of the lenses. Although a direct relationship between the lens ionic charge and water content and the ability of fungi to form biofilm could not be established, these data confirm previous findings that irregular surface texture of materials affect both cellular morphology and biofilm mass [58].

\subsubsection{Synthetic Media and Flow Systems Mimicking In Vivo} Conditions. The physiological specificity of infection sites is also an important factor, and efforts have been made to reproduce some major environmental cues in vitro, such as mimicking the blood flow or the urine. Biofilms grown in synthetic urine medium were comparable to those grown in the commonly used cell culture RPMI medium [59]. And time course studies revealed that the development of both types of biofilm followed a similar pattern, with an initial adherence phase, followed by growth, proliferation, and maturation. The biofilms differed slightly in their architecture, as biofilms grown in synthetic urine medium seemed to be less complex and less dense, with a larger proportion of yeast cells rather than elongated cells. Increased nutritional supply promoted biofilm formation in 
another model of artificial urine medium, highlighting once again the importance of reproducing as closely as possible the physiological conditions to gain relevant information [60]. C. tropicalis biofilms were also characterized in artificial urine medium, on urinary catheters in a flow model [61]. Cells were able to colonize the catheters in the presence of the artificial urine medium and to detach from these silicone catheters, illustrating their capacity to colonize distal sites.

Biofilms grown in static conditions have been predominantly studied, in comparison to flow-based systems, due to a low cost, a rapid processing of large number of samples, and limited technical requirements. However, in order to maintain their niches in dynamic environments, biofilms in vivo endure shear forces generated by the constant flow of physiological fluids [62]. Gene expression analyses revealed only a marginal difference between biofilms grown in static conditions, such as microtiter plates or serumtreated catheters, and those grown in a flow system in microfermentors [44]. Interestingly, the biofilm transcriptomes were not strongly affected by factors such as nutrient flow and aerobiosis, in contrast to the gene expression of free-living cells. However, a few studies indicated that biofilms grown under flow conditions, in CDC reactors or modified Robbins devices, contain more extracellular matrix and more biomass [10, 43, 45]. Mature biofilms formed in a flow of replenishing nutrients consist of a dense network of yeast cells, pseudohyphae, and hyphal cells. In a simple flow model, using a silicone strip placed in a conical tube, C. albicans biofilms grew thicker than biofilms grown in static conditions, and grew faster as an 8-hour-grown flow biofilm had similar biomass as a 24-hour-grown static biofilm [46]. The authors speculated that uninterrupted food supply prohibited adverse conditions, such as nutrient starvation and toxic accumulation, and hence promoted rapid cell proliferation. A parallel study, using a rotating disc system (RDS) to impose shear forces at physiological levels to biofilms developed on catheter pieces, illustrated similar results as biofilms under shear stress grew thinner but denser than those in no-flow conditions [47]. In the RDS model, less cells adhered at first, but by $24 \mathrm{~h}$ biofilms displayed similar metabolic activity and dry weight as those obtained in the static model. Suggestions that explained the increased growth rate in shear conditions included an increased rate of maturation in these conditions and a natural selection of more robust cells capable of withstanding the fluid friction by growing faster.

2.1.3. High-Throughput Biofilm Models. Another important aspect of in vitro biofilm modelling is the development of high-throughput systems of particular interest in the largescale screening of antibiofilm molecules. Most studies so far have made use of the 96-well microtiter plate assay [40]. In this model, biofilms are formed directly on the bottom of the wells, and the quantification method is based on the ability of sessile living cells to reduce tetrazolium salt (XTT) to water-soluble orange formazan compounds. In an effort to upscale biofilm production, a $C$. albicans biofilm chip system ( $\mathrm{CaBChip)}$ has recently been developed by Srinivasan et al. [42]. The high-density microarray platform is composed of more than 700 independent and uniform nanobiofilms encapsulated in a collagen matrix and provides the first miniature biofilm model for C. albicans. Despite the several-thousand-fold miniaturization, the biofilms formed on the chip displayed phenotypic characteristics, such as a multilayer of yeast, pseudohyphae and hyphal cells, and a high level of antifungal drug resistance, consistent with those of biofilms formed by standard methods. However, echinocandins were not proficient to eradicate biofilm in this system, potentially due to their binding to the collagen matrix. In a second generation of the biofilm chip, other nonprotein matrices will be investigated. While this system steps-up the number of biofilms that can be produced at once in static conditions, the next step may be to develop high-throughput flow biofilm systems adapted to Candida spp. Such a tool has been described based on a device comprised of microfluidic channels that provide fluid flow to 96 individual bacterial biofilms [63]. The effects of antimicrobial agents on the biofilms were rapidly screened, and viability was quantified by fluorescence measurements. These high-throughput techniques will certainly contribute greatly to the discovery of novel antibiofilm molecules.

\subsection{In Vivo Models of Candida Biofilms}

2.2.1. Biofilm Models on Inert Substrates. In vivo models are undisputedly required to appreciate the hostile environment that conditions biofilm formation (Table 2). A few Candida biofilm models, mostly associated to catheter infections, have been developed in several rodents, giving insights on the in vivo biofilm structure and the efficacy of various antifungal agents [70]. The catheter-related in vivo biofilm models resulted in biofilm formation within $24 \mathrm{~h}$ and consisted of complex structures of yeast and elongated cells embedded in extracellular matrix, similar to those observed in in vitro model systems [8]. While susceptibility to azoles was reduced in these models, liposomal amphotericin B lock therapy and treatment with caspofungin or chitosan proved to be efficient against in vivo biofilms [64, 65, 71]. Central venous catheter models (CVCs) are also useful for the investigation of the kinetics and occurrence of dissemination of the microorganisms to other organs, demonstrated by colonisation by $C$. albicans of the kidneys in the rat model [8]. In addition, the development of a CVC model in mice will allow comparison to other modes of infection, in particular to the commonly used disseminated candidiasis by tail vein infection. A murine model for catheter-associated candiduria was recently developed and illustrated the role of Candida biofilms in the persistence of the urinary tract infection [66]. It also outlined differences between murine and human catheter-related candiduria in terms of bladder inflammation and fungal burden in the urine. In another catheter-related Candida-associated infection model, we developed a subcutaneous foreign body system suitable for C. albicans [9]. This model, of nondisseminated nature, allowed the study of biofilm development for long periods of time (Figure 1) but required the use of immunosuppression treatment of the animals due to the high inflammatory response associated with implant of foreign devices. However, efficacy of the 
TABle 2: Candida biofilms in vivo models.

\begin{tabular}{|c|c|c|}
\hline Models in vivo & Device & Developed in \\
\hline \multirow[b]{3}{*}{ Catheter-associated models } & (i) Central venous system & Rat $[8]$, rabbit $[64]$, mouse $[65]$ \\
\hline & (ii) Candiduria model & Mouse $[66]$ \\
\hline & $\begin{array}{l}\text { (iii) Subcutaneous foreign body system } \\
\text { (biofilms developed after } 2 \text { to } 6 \text { days in } \\
\text { infected implated catheter fragments) }\end{array}$ & $\begin{array}{l}\text { Rat (immunosuppressed before and during } \\
\text { biofilm development) [9] }\end{array}$ \\
\hline \multirow{2}{*}{$\begin{array}{l}\text { Candida-associated denture stomatitis } \\
\text { models }\end{array}$} & $\begin{array}{l}\text { (i) Acrylic denture material attached to } \\
\text { the hard palate (biofilms developed } \\
\text { between the hard palate and the device) }\end{array}$ & $\begin{array}{l}\text { Rat (immunosuppressed on day of infection) } \\
\text { [67] }\end{array}$ \\
\hline & $\begin{array}{l}\text { (ii) Custom fitted denture system (cast } \\
\text { fabrication of a fixed part that is attached } \\
\text { to the posterior palate and a removable } \\
\text { part fitted to the anterior palate) }\end{array}$ & Rat $[68]$ \\
\hline Mucosal model of oropharyngeal candidiasis & $\begin{array}{l}\text { Biofilms developed on the tongue after } \\
\text { infection by swabbing and drinking water } \\
\text { contaminated with Candida cells }\end{array}$ & $\begin{array}{l}\text { Mouse (immunosuppressed on day of infection) } \\
{[12]}\end{array}$ \\
\hline Vaginitis model & In vivo and ex vivo models & $\begin{array}{l}\text { Mouse (treated with estradiol prior infection) } \\
{[69]}\end{array}$ \\
\hline
\end{tabular}

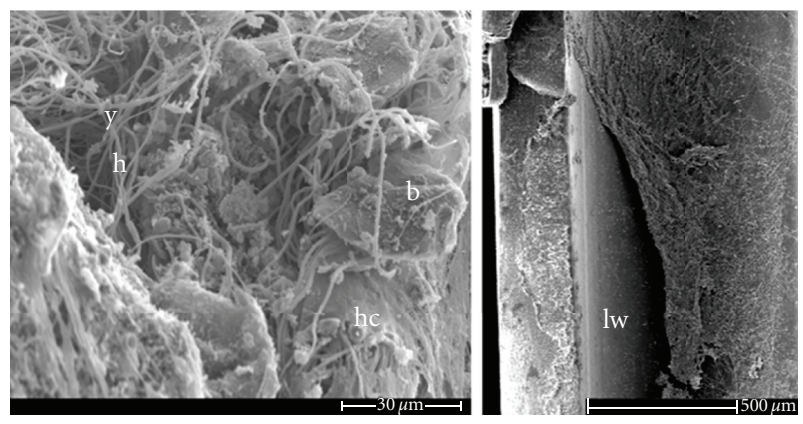

FIGURE 1: Scanning electron microscopy images of wild type Candida albicans biofilms developed in vivo in the denture model (left panel) and in the subcutaneous model (right panel). Elements such as hyphal cells (h), yeast cells (y), bacterial cells (b), host cells (hc) and catheter lumen wall (lw) are highlighted. Images were adapted from the work of Nett et al. [67], and S. Kucharíková and P. Van Dijck (MCB Laboratory, VIB, K.U. Leuven, unpublished data), respectively.

echinocandin anidulafungin, by intraperitoneal injections, was demonstrated against $C$. albicans biofilm in this in vivo system [72]. These in vivo models are all suited for further study of novel antifungal therapies and for the use of novel material technologies, including less adherent surfaces and material coating with fixed or releasing antifungal agents (see the next section).

A relatively cost- and time-effective Candida biofilm model on acrylic denture material, which does not require the ex vivo mold process, was illustrated recently [67]. In this rat model, biofilms developed between the hard palate and the denture material, following Candida inoculation in that $1 \mathrm{~mm}$ space (Figure 1). Fungal invasion of the palate and the tongue and neutrophils infiltration also occurred, indicating that the model was consistent with that of acute human denture stomatitis. Interestingly, the denture model offers the possibility to study mixed biofilm structure and behaviour in response to antimicrobial treatments, as the biofilms were composed of both bacterial and fungal cells. Finally, biofilms developed on the denture model were inherently resistant to fluconazole, in accordance with previous findings $[8,72]$, but also to the echinocandin micafungin, in contrast with previous investigations performed in a different model [73]. A plausible explanation suggested by the authors is that the mixed biofilm nature combined with the specific site of infection, the oral cavity, is the cause of that antifungal resistance. An alternative rat model of Candida-associated denture stomatitis recently described differs by the use of animal-fitted devices [68]. In this system, a removable part of the device makes the replacement of the infected device a relatively easy step. These models promise to deliver an alternative mean of testing novel antibiofilm molecules.

2.2.2. Biofilm Models on Biotic Surfaces. Tools and models to study biofilm formation developed on implanted materials are numerous and indicative of the increased medicinal use of such implants. Biofilms formed on live surfaces are much less characterized, yet they are recognized as causing or aggravating numerous chronic diseases [74]. Besides dental plaques, few reports have investigated biofilm development in clinical samples. Biotic biofilms are poorly understood as tissue samples are sparse and not easily accessible. The oral cavity is an accessible in vivo model for studying protein-surface interactions and has been well characterized for bacterial biofilm [75]. A mucosal model of oropharyngeal candidiasis was recently proposed to characterise C. albicans mucosal biofilms in situ in mice [12]. Keratin, originating from desquamating epithelial cells, constituted a large proportion of the biofilm matrix. First evidence was given that epithelial cells, neutrophils, and commensal oral bacteria co-exist within the fungal mucosal biofilm developed on mouse tongue. Bacteria were mostly found on the apical part of the biofilm, and very few were seen to 
invade the tongue epithelium layer. This model highlights the complexity of mucosal biofilms, as host elements and commensal organisms contribute in an active or passive manner to the structure of the biofilms.

C. albicans can also form biofilms on the vaginal mucosa, illustrated by two in vivo and ex vivo models in immunocompetent estradiol-treated mice [69]. C. albicans vaginal biofilms consisted of yeast and hyphal cells embedded in extracellular material, illustrated by ConA staining of the interspersed matrix. In the ex vivo model using vaginal explants, no exogenous nutrients were provided, yet biofilms were formed most likely by scavenging host nutrients.

Host-pathogen interactions in biofilm settings have not yet been elucidated, but comparison between these models promises to identify model-specific fungal and host elements.

2.3. Mixed Species Candida Biofilms. The relative contribution and the role of bacteria-Candida interactions in the pathogenesis of mucosal infections are yet to be established. However, there is clear evidence that multimicrobial interactions have a central role in the context of human disease [76]. For example, microbial diversity was illustrated in a biofilmrelated infection of the urinary tract [77]. Out of 535 clinical samples of urinary catheters, Candida spp. were identified among the 39 different microbial taxa isolated. Single-species samples represented $12.5 \%$ only. C. albicans was isolated in 141 samples, and other Candida species were present in other 82 samples. Biofilm formation ability of each isolated strain was quantified in vitro, yet not in an artificial urine medium, and cut-off values were used to define no, weak, intermediate, and strong biofilm producers. C. tropicalis isolates were the strongest biofilm producers among the Candida species. Certain species of bacteria did not show biofilm formation ability in this study. These data illustrates the fact that, in multispecies biofilms, some have a great potential to cause biofilm-based infections, while others may be more passive members of the structured community. Commensalism, mutual cooperation, and antagonism make the interactions within mixed biofilms complex [78, 79]. A summary of bacteria-Candida interactions and their effect on fungal development is provided in Table 3. Bacteria can interact with $C$. albicans cells within mixed biofilms, and in particular with hyphal cells. The methicillin-resistant Gram-positive Staphylococcus aureus had the highest hyphal association, in comparison to S. epidermidis, Strepococcus pyogenes, Pseudomonas aeruginosa, Bacillus subtilis, and Escherichia coli in decreasing order, respectively [80]. However, interaction between $S$. aureus and C. albicans did not result in reduced or altered biofilm viability. In another study, addition of bacteria to preformed Candida biofilms in vitro had an antagonistic effect on biofilm cell mass, often in a cell-density-dependent manner [81]. With all inoculums tested, $P$. aeruginosa reduced significantly the fungal biofilm mass when added during the first few hours of biofilm development. In a different experimental assay, preformed bacterial biofilms significantly reduced adhesion and biofilm growth of C. albicans [82]. Moreover, simultaneous addition of bacteria and C. albicans cells showed that in all cases fungal adhesion was decreased, whereas bacterial biomasses were not affected.

Hypotheses of synergistic relationships between microbes have been suggested, and in particular within mixed biofilm communities [83]. For example, bacterial adhesion was observed on the tongue mucosa of $C$. albicans-infected animals but not of noninfected animals, in a mucosal model of oropharyngeal candidiasis [12]. Synergistic cooperation can also perturb susceptibility to antimicrobial treatment. For example, $S$. aureus resistance to vancomycin was enhanced in mixed biofilms with viable C. albicans cells, whereas susceptibility of the fungal cells to the antifungal amphotericin B was not altered [84]. Binding of the fungus to the bacterial cells occurs via the Candida-specific adhesin proteins, including Als3, Eap1, and Hwp1, as demonstrated by heterologous expression of these cell wall proteins in the model yeast Saccharomyces cerevisiae [85]. The role of adhesins in single- and multispecies biofilm formation is not discussed here but can be found in previous reports [86-88].

\section{Antibiofilm Strategies: Research and Development}

The current therapies against fungal diseases [96], employing one of the five classes of antifungals (polyenes, pyrimidine analogues, allylamines, azoles, and echinocandins) administrated orally or intravenously, are not discussed in this paper. Each antifungal compound has advantages and limitations related to its spectrum of activity and mode of action. The susceptibility of Candida biofilms to the current therapeutic agents remains low, with the exception of the echinocandins [97, 98]. However, these compounds have been employed in different approaches, such as lock therapy or material coating as releasing agent. These alternative methods and their perspective of usage are discussed below.

\subsection{Lock Therapy Approach and Prevention against Catheter-} Related Blood Stream Infections. Nosocomial infections associated with medical devices represent a large proportion of all cases of hospital-acquired infections [99]. In particular, insertion of any vascular catheter can result in a catheterrelated infection, as microorganisms can colonise catheter external and internal surfaces. Some of the favourite niches of colonisation of Candida spp. include indeed vascular and urinary catheters and ventricular assist devices, which can be accompanied with high mortality rates [100]. Adherence to the catheter surface, facilitated by host proteins such as fibronectin and fibrinogen, can then lead to biofilm formation [101]. The antimycotic lock therapy approach is currently recommended and employed in treating catheterrelated bloodstream infections (CRBSI), in particular for long-term catheters, according to the Infectious Diseases Society of America guidelines [102]. However, lock therapeutic treatment is pathogen- specific as catheter removal is recommended for CRBSI caused by Candida species and Staphylococcus aureus. The lock therapy involves the instillation of high doses of an antimicrobial agent (from 100 - to 1000 -fold the minimal inhibitory concentration, 
TABLE 3: Interspecies relationship with Candida spp. growth and biofilm development.

\begin{tabular}{|c|c|c|}
\hline Bacterial species & Effect on C. albicans hyphal growth & Effect on Candida biofilm \\
\hline Staphylococcus aureus (+) & Associates to hyphal cells (56\%) [80] & $\begin{array}{l}\text { No antagonistic effect in dual biofilms with } \\
\text { C. albicans (BacLight LIVE/DEAD assay) [80] }\end{array}$ \\
\hline Staphylococcus epidermidis $(+)$ & Associates to hyphal cells (25\%) [80] & $\begin{array}{l}\text { Reduced adhesion and biofilm formation by } \\
\text { a glycocalyx producer strain (CFU counts) [82] }\end{array}$ \\
\hline Streptococcus pyogenes $(+)$ & Associates to hyphal cells (25\%) [80] & \\
\hline $\begin{array}{l}\text { Streptococcus mutans and } \\
\text { Streptococcus intermedius }\end{array}$ & S. mutans inhibits hyphal formation $[89,90]$ & $\begin{array}{l}\text { No significant effect on biofilm viability at densities } \\
\text { ranging from } 6.25 \cdot 10^{5} \text { to } 1 \cdot 10^{7} \text { cells/mL (bacteria } \\
\text { added to preformed 3-hour-old biofilms; } \\
\text { polystyrene in vitro model; CFUs analyses) [81] }\end{array}$ \\
\hline Streptococcus gordonii $(+)$ & Stimulates hyphal growth [91] & Promotes mixed biofilms with C. albicans [91] \\
\hline Pseudomonas aeruginosa (-) & $\begin{array}{l}\text { (i) Associates to hyphal cells (17\%) [80] } \\
\text { (ii) Reduced hyphal growth in C. albicans-P. } \\
\text { aeruginosa dual biofilms [81] } \\
\text { (iii) Binds hyphae and kill C. albicans [92] }\end{array}$ & $\begin{array}{l}\text { (i) Reduced adhesion and biofilm formation by a } \\
\text { nonglycocalyx producer strain (CFU counts) [82] } \\
\text { (ii) Reduction of biofilm mass ranging from } 40 \% \text { to } \\
80 \% \text { in a density-dependent manner [90] } \\
\text { (iii) Mutual biofilm inhibition between } \mathrm{Pa} \text { and } \\
\text { C. albicans, } \mathrm{C} \text {. krusei and C. glabrata; decreased } \\
\text { biofilm formation of C. parapsilosis and } C \text {. tropicalis } \\
\text { in presence of } \mathrm{Pa} \text {; increased CFUs of } \mathrm{Pa} \text { in presence } \\
\text { of } \mathrm{C} \text {. tropicalis [93] }\end{array}$ \\
\hline Escherichia coli $(-)$ & Associates to hyphal cells (5.7\%) [80] & $\begin{array}{l}\text { (i) Reduction of biofilm mass ranging from } 50 \% \text { to } \\
80 \% \text { [81] } \\
\text { (ii) Mutual decrease in biofilm cell mass between } E c \\
\text { and C. albicans; inhibition of biofilm development } \\
\text { by C. tropicalis, C. parapsilosis, C. krusei, and } C \text {. } \\
\text { dubliniensis; increased Ec cell numbers within } C \text {. } \\
\text { tropicalis and C. dubliniensis biofilms [94] }\end{array}$ \\
\hline Lactobacillus acidophilus & & Inhibition of viable biofilm cell mass by $40 \%$ [ 81$]$ \\
\hline Bacillus subtilis & Associates to hyphal cells $(2.5 \%)[80]$ & \\
\hline Actinomyces israelii $(+)$ & & Some inhibition of biofilm at high densities [81] \\
\hline $\begin{array}{l}\text { Prevotella nigrescens and } \\
\text { Porphyromonas gingivalis }\end{array}$ & $\begin{array}{l}\text { Inhibition of C. albicans hyphal development } \\
\text { [95] }\end{array}$ & $\begin{array}{l}\text { Reduction of C. albicans biofilms, only at high } \\
\text { densities [81] }\end{array}$ \\
\hline $\begin{array}{l}\text { Klebsiella pneumoniae, Serratia } \\
\text { marcescens, and Enterobacter } \\
\text { cloacae }\end{array}$ & & Decreased biofilm formation (CFU counts) [82] \\
\hline
\end{tabular}

(MIC)) directly into the catheter in order to "lock" it for a certain period of time (from hours to days) [103].

Few reports are currently available on the usage of antifungal lock solutions in clinical practice, but they seem to indicate the curative effect of this kind of treatment $[104,105]$. In vitro studies are more prevalent at the moment and seem to also favour the use of antifungal lock therapy to eliminate Candida spp. biofilms, and in particular with the usage of echinocandins [106]. For example, biofilm metabolic activity formed on silicone by $C$. albicans and C. glabrata could be effectively reduced by a $12 \mathrm{~h}$ lock treatment with micafungin (at 100-500x MIC), which was shown to persist for up to 3 days [107]. Caspofungin had an intermediate effectiveness in the same study, as its activity did not persist as long against C. glabrata biofilms. While these results are promising for potential use of the lock technique to treat infected catheters, $100 \%$ biofilm inhibition could not be achieved. Sterilization of catheters was obtained in vivo by lock treatment with amphotericin $B$ lipid complex (ABLC) in a rabbit model of catheter- associated C. albicans biofilm [108]. However, in this study, the lock solution was administrated a few hours a day for a prolonged period of time (7 days). Synergistic antibiofilm combinations, used as lock solutions, between classical antimicrobial agents and other compounds such as the mucolytic agent $\mathrm{N}$-acetylcysteine, ethanol, or the chelating agent EDTA, are also effective against $S$. epidermidis and $C$. albicans individual and mixed biofilms [109]. In a similar approach, recent results suggest that the combination of antibacterial agents with Gram-positive activity, including doxycycline and tigecycline, with known antifungals, such as AMB, caspofungin, and fluconazole, can be useful for the treatment of C. albicans biofilms [110,111].

The prevention of CRBSI has also been the focus of research and randomized controlled trials [112]. In a systematic assessment, Hockenhull et al. [113] showed the clinical effectiveness of CVCs treated with anti-infective agents (AI-CVC) in preventing CRBSI. While trials are still required to determine the most cost and clinicaleffective anti-infective product, the routine usage of AI-CVC 
will often be limited if appropriate use of other practical care behaviour is not employed in intensive care units. Antifungal impregnated CVCs have been tested in animal models. The echinocandin caspofungin was employed to prevent $C$. albicans biofilm formation in a biofilm model in mice. C. albicans biofilm formation was greatly reduced in CVCs that had been pretreated for $24 \mathrm{~h}$ with high doses of caspofungin. The dissemination to the kidneys was also reduced by such therapy [65]. Similarly, the use of chitosan, a polymer isolated from crustacean exoskeletons, as a pretreatment of catheters to prevent $C$. albicans biofilm formation was validated in a CVC biofilm in vivo model [71]. The use of lock technique or preventive impregnation of antifungals in combating catheter-associated infection seems promising, but not yet convincing on a cost effective point of view as huge doses are still needed to eradicate fungal growth.

3.2. Material Coating and Novel Antibiofilm Surfaces. A developing field of research focuses on the usage of modified materials or coated surfaces to prevent adherence and biofilm development. Implant materials are prone to biofilm formation affecting health in general and duration of the implant in particular. Surface characteristics, such as surface roughness, surface free energy, and chemistry, can influence the type and the feature of the biofilms $[114,115]$. For example, $C$. albicans adhesion is enhanced if the roughness of the denture materials is increased [116]. It is nowadays conceivable that coatings may be engineered to promote selective adhesion, with possible attachment to cell tissue (for implant in bone contact) but not to microbes. They may also address the second phase of biofilm development involving quorum sensing, by inhibiting cell-cell communication signals [117, 118]. Biomaterial modifications as a way to prevent biofilm development have been the focus of intense research, in particular in the field of bacterial biofilms [119], but the latest findings on their impact on Candida biofilms are discussed next.

3.2.1. Surface Modifications. Surface properties of medical devices constitute a major factor contributing not only to the stability in the body but also to their performance and lifetime in vivo and their colonization by microorganisms. In that matter, albumin adhesion is beneficial since it has been shown to prevent binding of microorganisms, while fibrinogen has the opposite effect [120]. Chemical grafting of polyethylene and polypropylene surfaces, functionalized with cyclodextrins, yielded a change in protein adsorption profile of these polymers, by promoting adsorption of albumin and reducing adhesion of fibrinogen to the material surface [121]. In addition, these modified substrates incorporated well the antifungal agent miconazole, leading to reduced biofilm formation by $C$. albicans in vitro. Modified polyethylene and silicone rubbers proved to be very efficient in inhibiting C. albicans biofilm formation in vitro [122]. These cytocompatible materials were also capable of releasing for several hours considerable amount of an anionic antimicrobial drug, nalidixic acid, suggesting their use as drug-eluting systems.
Modifications of polyurethanes dental biomaterials by addition of surface-modifying end groups were successfully employed to manage C. albicans biofilm formation [123]. In addition, correlation between contact angle and biofilm formation was surface dependent. Increased hydrophobicity resulted in increased metabolic activity of the biofilms grown on polyetherurethane, while they inversely correlated for biofilms formed on polycarbonate surfaces. Addition of $6 \%$ polyethylene oxide to Elastane $80 \mathrm{~A}$ showed to be the best combination as no biofilm could be observed on that surface. Biofilms on voice prostheses consist of mixed populations that can include C. albicans. Modification of the silicone surface of the prostheses has been employed to limit $C$. albicans colonization, as opposed to incorporation of antimicrobial agents in order to avoid the occurrence of resistance [124]. Silicone disks grafted with $\mathrm{C} 1$ and C8 alkyl side chains reduced adherence and biofilm formation of $C$. albicans by up to $92 \%$. Longer side chains did not show as good results, and combinations of quaternizing agents did not work synergistically either. Similarly, grafting of cationic peptides, such as the salivary peptide Hst5 and synthetic variants, onto silicone rubber, inhibited biofilm formation by up to $93 \%$, in a peptide-dependent manner [125].

3.2.2. Surface Coatings. Fungicidal or fungistatic materials have been employed to fabricate or coat the surfaces of medical devices and have a great potential in reducing or eliminating the incidence of biofilm-related infections. Dental resin material coated with thin-film polymer formulations containing the polyene antifungals nystatin, amphotericin B, or the antiseptic agent chlorhexidine, were used in C. albicans biofilm assays [126]. Biofilm reduction was the greatest on chlorhexidine containing polymers, while the other formulations were much less efficient. Similarly, multilayered polyelectrolyte thin films containing an antifungal $\beta$-peptide incorporated within the layers of the films inhibited the growth (and hyphal formation) of C. albicans by $74 \%$ after $2 \mathrm{~h}$ of contact [127].

The polysaccharide dextran is widely used in medicine and is also one of the main components of dental plaque. Cross-linked dextran disks soaked with amphotericin B solutions, described as amphogel, kills fungi within 2 hours of contact and can be reused for almost 2 months without losing its efficacy against C. albicans [128]. This antifungal material is biocompatible and could be used to coat medical devices to prevent microbial attachment. It was recently used for local antifungal therapy in the form of injectable cross-linking hydrogels [129]. Nitric oxide can antagonise cell proliferation by signalling rather than by toxic effect. It regulates bacterial biofilm dispersal and has also been employed in releasing xerogel to attenuate C. albicans adherence and biofilm formation [130]. The nitric-oxidebased method is still at the experimental level, due to poor water solubility and stability.

Coating of medical material surfaces has been employed and tested with several types of coating molecules, including the naturally occurring polymer chitosan and antimicrobial peptides such as Histatin 5 (Hst5). Surfaces coated with the polymer reduced the viable cell number in biofilms by 
more than 95\%, in the case of C. albicans and also for many bacteria such as Staphylococcus aureus [131]. Chitosan, which is proficient against a wide range of pathogenic microbes, disrupts cell membranes as cells settle on the surface. The use of such polymer offers a biocompatible tool for further coating design of medical devices. Acrylic disks precoated with Hst5 prove to be efficient in inhibiting biofilm formation of C. albicans, especially in the later stage of development, while biofilm sensitivity to the antimicrobial peptide was the same as the one of free-living cells [132]. The utility and potential of selected peptides, as therapeutic molecules, including the $\beta$-glucan synthesis inhibitors, the histidine-rich peptides, and the LL-37 cathelicidin family are being determined and could be used as coating compounds against adherence and biofilm formation $[133,134]$.

The possible applications of biomaterial modification remain to be clearly established and approved. Shift from a commensal bacterial biofilm to a more pathogenic biofilm involving Candida spp. in the oral cavity for instance is believed to be more influenced by mucosal inflammation and the general well-being of the host than on the nature and surface properties of the material itself [135]. However, development of materials that can fully abolish microbial adherence is a promising perspective against biofilm formation. The discrepancy between antimicrobial coatings killing the biofilm-proficient organisms and antimicrobial releasing coatings to prevent biofilm formation is a current issue.

\subsection{Quorum Sensing Molecules and Natural Byproducts.} Adhesion and biofilm formation by $C$. albicans cells can be modulated by physical and chemical signals from the oral bacterium Streptococcus gordonii [91]. Indeed, most Streptococcus species possess the antigen I/II, a cell-wallanchored protein receptor that mediates binding to C. albicans. Moreover, C. albicans hyphal and biofilm development are greatly enhanced by $S$. gordonii, which also relieved the fungal cells from the repressing effect of the quorum sensing molecule farnesol [91]. Farnesol, a sesquiterpene and signalling molecule produced by C. albicans, represses biofilm formation in vitro [136]. Conversely, tyrosol, a 2(4-hydroxyphenyl) ethanol derivative of tyrosine, accelerates hypha production in the early stages of biofilm development and is secreted at least $50 \%$ more by biofilm cells than by planktonic cells [137]. Several studies demonstrated that farnesol actually increases fungal pathogenicity in animal models, potentially by interfering with normal progression of cytokine induction [138-140]. Analogs of farnesol have been identified that fail to induce pathogenicity and yet retain farnesol ability to block hyphal development [141]. While these analogs did not protect mice from candidiasis, they may be of interest in biofilm inhibition. Indeed, a number of molecules with farnesol-like activity, that can induce the shift to the yeast form of growth, have been identified in Gramnegative bacteria. For instance, the signalling molecule, homoserine lactone, produced by Pseudomonas aeruginosa represses C. albicans filamentation [142]. P. aeruginosa also produces several phenazines that exhibit antifungal activity against $C$. albicans [143]. Uptake of the phenazines generated reactive oxygen species production and led to fungal cell death. In mixed biofilms, binding of the toxins to the fungal cells has a negative influence on C. albicans growth.

In a different approach, Valle et al. [144] demonstrated that the use of nonantibiotic molecules, such as polysaccharides, produced by competitive commensal organisms can antagonize biofilm formation. A better knowledge of the microbial community behaviour and in particular of the interaction between commensal and pathogen organisms would help to combat predominance of the infectious or disease causative agents. In this scheme, natural products produced by cells within a biofilm contribute to the dynamic of the community and may play an antiadhesion role for nonwanted other microorganisms [145]. Bacterial lipopolysaccharides also modulate adhesion and biofilm ability of several Candida species, in an interspecies-dependent manner [146]. It is not known how mixed populations affect the host immune response in response to infection. The overall population behaviour results from a potential selective advantage to either or both species. While communication is the key, interpretation is the code. Identification and alterations of the communication signals would certainly result in a better understanding of how species coexist and permit a better control of biofilm formation [147]. Targeting quorum sensing molecules or associated signalling mechanisms is an open field of research at present, but the use of quorum quenching enzymes or quorum sensing inhibitors naturally produced by other species could help in the finding of novel antibiofilm agents [148, 149].

\subsection{Host Responses to Biofilms: Perspective of Immunotherapy.} With the number of people considered at high risk for microbial infections constantly increasing, immunotherapy seems to offer a great potential despite the complexity of the interaction between the host defence system and the pathogen [150]. The ability of human pathogens, such as Candida spp., to cause infections depends on a constant and sometimes discontinuous battle between the pathogen and the host immune system [151]. Recognition of Candidaspecific pathogen-associated molecular patterns (PAMPs) by dedicated pattern recognition receptors (PRRs) such as Tolllike receptors and lectins activates the innate effector cells (macrophages, dendritic cells, and neutrophils), which in turn produce a variety of soluble factors, including cytokines and chemokines [152]. However, little is yet known about the interactions between human phagocytes and Candida spp. biofilms, while immunotherapeutic treatment against candidiasis has been undertaken [153, 154]. Chandra et al. [155] demonstrated that adherent peripheral blood mononuclear cells (PBMCs) enhanced the ability of $C$. albicans to form biofilm. They also observed that phagocytosis of the fungal cells within a biofilm did not occur while their freeliving counterparts were phagocytosed. These data defined the novel concept that Candida biofilms seem to have an immunosuppressive effect. Inactivated PBMCs on the other hand did not induce this enhanced growth behaviour, nor did lipopolysaccharide-activated PBMCs, suggesting that the stimulated biofilm formation resulted from (a) Candidabiofilm-induced secretory factor(s). Indeed, the cytokine profile of PBMCs following coculture with planktonic or 
biofilm cells of $C$. albicans differed greatly, with IL- $1 \beta$ as the cytokine most highly overexpressed by contact with biofilms. Supporting these data, a recent study showed that phagocytes alone induced much less damage to biofilms than they did to free-living cells or to resuspended biofilm cells, which lacked the overall structure of biofilms and most of the matrix [156]. Using confocal laser scanning microscopy, Katragkou and coworkers deducted that human phagocytes looked like unstimulated cells, presenting a rounded shape when in presence of biofilms. This was also confirmed by a reduced cytokine production in a biofilm-phagocyte coculture, compared to a planktonic cells-phagocytes mix. Phagocytes appeared entrapped within the structured network of cells and matrix and were unable to internalize cells within biofilms. Moreover, C. albicans and C. parapsilosis biofilms were more susceptible to the additive effects between phagocytic host defence and the echinocandin anidulafungin than to each separately and to the combination of the azole voriconazole with phagocytes $[156,157]$. These data validate the findings that echinocandins can influence host cell interactions with biofilm [158].

Pathogens have evolved many mechanisms of defence to avoid being recognized by the host environment [159-161] . C. albicans can evade immune attack by masking its cell wall $\beta$-glucan component, a potent pro-inflammatory signature carbohydrate, under a thick layer of mannoproteins. Clear evidence showed that exposing the $\beta$-glucans by treatment with the antifungal drug caspofungin elicited a stronger immune response [158]. These data suggest that echinocandin treatment may enhance immunity [162]. Masking of $\beta$ glucans depends on a complex network of cell wall remodelling, and targeting these regulatory processes may identify novel antifungal possibilities. For example, disruption of the MAPK pathway regulated by the extracellular signal-induced Cek1 kinase triggered a greater $\beta$-glucan exposure, which resulted in an enhanced immune response compared to the wild-type strain [163]. There are conflicting data regarding the role of the $\beta$-glucan receptor Dectin-1, expressed widely on phagocytes, in antifungal immunity [164]. However, studies suggested that Dectin-1 is required for fungal killing and induction of early inflammatory responses. These findings are of interest for biofilm recognition by the immune system, as $\beta-1,3$-glucans are found in high amounts in the extracellular matrix of Candida biofilms in vitro and in vivo $[10,12,165]$. Biofilms developed on soft tissue are associated with infiltration of the infected sites by neutrophils, which can then confer innate immune protection [166]. In $C$. albicans, Hyr1, encoding a GPI-anchored cell wall protein, has been shown to confer resistance to neutrophil killing in vitro and in the oral mucosal tissue biofilm model [12, 167]. In addition, vaccination with a recombinant Hyrlp protected mice against hematogenously disseminated candidiasis. Immunotherapeutic strategies, such as vaccination, anti-Candida antibodies, and cytokine therapy, are under investigation to treat Candida infections [168]. However, their applicability in treating biofilm-related infections is still in a preliminary state. In that framework, recent data showed that pretreatment of $C$. albicans cells with antibodies targeting the complement receptor 3-related protein led to reduced adhesion and biofilm formation in vitro [169]. In another study, anti-C. albicans antibodies from chicken egg yolk were employed as antiadherent molecules [170]. While the adherence of $C$. albicans was reduced, biofilm inhibition was only observed in absence of serum, as the activity of the antibody was very much reduced against germ tubes, of which the formation is induced in the presence of serum. In vivo studies of the antibody-based approach remain to be investigated in the context of biofilms.

\section{Concluding Remarks}

The large panel of biofilm models suitable for Candida research highlights the diversity of niches in which the fungus can develop ranging from biotic to abiotic surfaces. However, the role and nature of host-pathogen interactions during biofilm formation are only starting to get unveiled. The search for an antibiofilm treatment is a complex subject which requires improved knowledge of the pathogen itself, and also of the host response to adhesion and biofilm formation, the properties of the substrates onto which biofilm develop, and the interactions within microbial communities. The field of chemoinformatics may assist the development of novel antibiofilm compounds, based on already identified good candidate molecules [171]. This approach may also reveal better coating agents for material surfaces that would persist long periods of time in vivo. The use of natural compounds, from dietary plants or probiotics, may also be considered as they are better tolerated by humans.

\section{Acknowledgments}

The authors would like to thank Bram Stynen, Joke Serneels, Sona Kucharikova, and Sneh Panwar for their critical reading of the paper. They are grateful to David Andes for providing the SEM image of Candida albicans biofilm. The original work included in this paper was supported by the Fund for Scientific Research Flanders (G.0242.04 and WO.004.06N).

\section{References}

[1] B. Meyer, "Approaches to prevention, removal and killing of biofilms," International Biodeterioration and Biodegradation, vol. 51, no. 4, pp. 249-253, 2003.

[2] A. Dongari-Bagtzoglou, "Pathogenesis of mucosal biofilm infections: challenges and progress," Expert Review of AntiInfective Therapy, vol. 6, no. 2, pp. 201-208, 2008.

[3] R. M. Donlan, "Biofilms: microbial life on surfaces," Emerging Infectious Diseases, vol. 8, no. 9, pp. 881-890, 2002.

[4] L. E. Davis, G. Cook, and J. William Costerton, "Biofilm on ventriculoperitoneal shunt tubing as a cause of treatment failure in coccidioidal meningitis," Emerging Infectious Diseases, vol. 8, no. 4, pp. 376-379, 2002.

[5] G. Ramage, J. P. Martínez, and J. L. López-Ribot, “Candida biofilms on implanted biomaterials: a clinically significant problem," FEMS Yeast Research, vol. 6, no. 7, pp. 979-986, 2006.

[6] L. R. Martinez and B. C. Fries, "Fungal biofilms: relevance in the setting of human disease," Current Fungal Infection Reports, vol. 4, no. 4, pp. 266-275, 2010. 
[7] G. Ramage, K. VandeWalle, B. L. Wickes, and J. L. LópezRibot, "Characteristics of biofilm formation by Candida albicans," Revista Iberoamericana de Micologia, vol. 18, no. 4, pp. 163-170, 2001.

[8] D. Andes, J. Nett, P. Oschel, R. Albrecht, K. Marchillo, and A. Pitula, "Development and characterization of an in vivo central venous catheter Candida albicans biofilm model," Infection and Immunity, vol. 72, no. 10, pp. 6023-6031, 2004.

[9] M. Řičicová, S. Kucharíková, H. Tournu et al., "Candida albicans biofilm formation in a new in vivo rat model," Microbiology, vol. 156, no. 3, pp. 909-919, 2010.

[10] M. A. Al-Fattani and L. J. Douglas, "Biofilm matrix of Candida albicans and Candida tropicalis: chemical composition and role in drug resistance," Journal of Medical Microbiology, vol. 55, no. 8, pp. 999-1008, 2006.

[11] T. S. Walker, K. L. Tomlin, G. S. Worthen et al., "Enhanced Pseudomonas aeruginosa biofilm development mediated by human neutrophils," Infection and Immunity, vol. 73, no. 6, pp. 3693-3701, 2005.

[12] A. Dongari-Bagtzoglou, H. Kashleva, P. Dwivedi, P. Diaz, and J. Vasilakos, "Characterization of mucosal Candida albicans biofilms," PLoS ONE, vol. 4, no. 11, Article ID e7967, 2009.

[13] M. Martins, P. Uppuluri, D. P. Thomas et al., "Presence of extracellular DNA in the Candida albicans biofilm matrix and its contribution to biofilms," Mycopathologia, vol. 169, no. 5, pp. 323-331, 2010.

[14] C. d'Enfert, "Biofilms and their role in the resistance of pathogenic Candida to antifungal agents," Current Drug Targets, vol. 7, no. 4, pp. 465-470, 2006.

[15] L. R. Martinez and A. Casadevall, "Cryptococcus neoformans biofilm formation depends on surface support and carbon source and reduces fungal cell susceptibility to heat, cold, and UV light," Applied and Environmental Microbiology, vol. 73, no. 14, pp. 4592-4601, 2007.

[16] E. Mowat, C. Williams, B. Jones, S. McChlery, and G. Ramage, "The characteristics of Aspergillus fumigatus mycetoma development: is this a biofilm?" Medical Mycology, vol. 47, no. 1, pp. S120-S126, 2009.

[17] R. Singh, M. R. Shivaprakash, and A. Chakrabarti, "Biofilm formation by zygomycetes: quantification, structure and matrix composition," Microbiology, vol. 157, no. 9, pp. 26112618, 2011.

[18] P. Uppuluri, A. K. Chaturvedi, A. Srinivasan et al., "Dispersion as an important step in the Candida albicans biofilm developmental cycle," PLoS Pathogens, vol. 6, no. 3, Article ID e1000828, 2010.

[19] S. L. Kuchma and G. A. O'Toole, "Surface-induced and biofilm-induced changes in gene expression," Current Opinion in Biotechnology, vol. 11, no. 5, pp. 429-433, 2000.

[20] M. Whiteley, M. G. Bangera, R. E. Bumgarner et al., "Gene expression in Pseudomonas aeruginosa biofilms," Nature, vol. 413, no. 6858, pp. 860-864, 2001.

[21] D. P. Thomas, S. P. Bachmann, and J. L. Lopez-Ribot, "Proteomics for the analysis of the Candida albicans biofilm lifestyle," Proteomics, vol. 6, no. 21, pp. 5795-5804, 2006.

[22] G. Vediyappan, T. Rossignol, and C. D’Enfert, "Interaction of Candida albicans biofilms with antifungals: transcriptional response and binding of antifungals to beta-glucans," Antimicrobial Agents and Chemotherapy, vol. 54, no. 5, pp. 20962111, 2010.

[23] C. Jayampath Seneviratne, Y. Wang, L. Jin, Y. Abiko, and L. P. Samaranayake, "Proteomics of drug resistance in Candida glabrata biofilms," Proteomics, vol. 10, no. 7, pp. 1444-1454, 2010.
[24] J. E. Nett, H. Sanchez, M. T. Cain, K. M. Ross, and D. R. Andes, "Interface of Candida albicans biofilm matrixassociated drug resistance and cellwall integrity regulation," Eukaryotic Cell. In press.

[25] P. Perumal, S. Mekala, and W. L. Chaffin, "Role for cell density in antifungal drug resistance in Candida albicans biofilms," Antimicrobial Agents and Chemotherapy, vol. 51, no. 7, pp. 2454-2463, 2007.

[26] D. Romero and R. Kolter, "Will biofilm disassembly agents make it to market?" Trends in Microbiology, vol. 19, no. 7, pp. 304-306, 2011.

[27] C. A. Kumamoto, "Candida biofilms," Current Opinion in Microbiology, vol. 5, no. 6, pp. 608-611, 2002.

[28] J. R. Blankenship and A. P. Mitchell, "How to build a biofilm: a fungal perspective," Current Opinion in Microbiology, vol. 9, no. 6, pp. 588-594, 2006.

[29] A. B. Estrela, M. G. Heck, and W. R. Abraham, "Novel approaches to control biofilm infections," Current Medicinal Chemistry, vol. 16, no. 12, pp. 1512-1530, 2009.

[30] A. Espinel-Ingroff, "Novel antifungal agents, targets or therapeutic strategies for the treatment of invasive fungal diseases: a review of the literature (2005-2009)," Revista Iberoamericana de Micologia, vol. 26, no. 1, pp. 15-22, 2009.

[31] J. Nett and D. Andes, "Candida albicans biofilm development, modeling a host-pathogen interaction," Current Opinion in Microbiology, vol. 9, no. 4, pp. 340-345, 2006.

[32] P. Cos, K. Toté, T. Horemans, and L. Maes, "Biofilms: an extra hurdle for effective antimicrobial therapy," Current Pharmaceutical Design, vol. 16, no. 20, pp. 2279-2295, 2010.

[33] T. Pereira-Cenci, D. M. Deng, E. A. Kraneveld et al., "The effect of Streptococcus mutans and Candida glabrata on Candida albicans biofilms formed on different surfaces," Archives of Oral Biology, vol. 53, no. 8, pp. 755-764, 2008.

[34] L. Li, M. B. Finnegan, S. Özkan et al., "In vitro study of biofilm formation and effectiveness of antimicrobial treatment on various dental material surfaces," Molecular Oral Microbiology, vol. 25, no. 6, pp. 384-390, 2010.

[35] J. P. Frade and B. A. Arthington-Skaggs, "Effect of serum and surface characteristics on Candida albicans biofilm formation," Mycoses, vol. 54, no. 4, pp. e154-e162, 2011.

[36] S. Silva, M. Henriques, A. Martins, R. Oliveira, D. Williams, and J. Azeredo, "Biofilms of non-Candida albicansCandida species: quantification, structure and matrix composition," Medical Mycology, vol. 47, no. 7, pp. 681-689, 2009.

[37] D. M. Kuhn, J. Chandra, P. K. Mukherjee, and M. A. Ghannoum, "Comparison of biofilms formed by Candida albicans and Candida parapsilosis on bioprosthetic surfaces," Infection and Immunity, vol. 70, no. 2, pp. 878-888, 2002.

[38] S. Silva, M. Negri, M. Henriques, R. Oliveira, D. W. Williams, and J. Azeredo, "Adherence and biofilm formation of nonCandida albicans Candida species," Trends in Microbiology, vol. 19, no. 5, pp. 241-247, 2011.

[39] A. A. Lattif, P. K. Mukherjee, J. Chandra et al., "Characterization of biofilms formed by Candida parapsilosis, $C$. metapsilosis, and C. orthopsilosis," International Journal of Medical Microbiology, vol. 300, no. 4, pp. 265-270, 2010.

[40] C. G. Pierce, P. Uppuluri, A. R. Tristan et al., "A simple and reproducible 96-well plate-based method for the formation of fungal biofilms and its application to antifungal susceptibility testing," Nature Protocols, vol. 3, no. 9, pp. 1494-1500, 2008.

[41] N. B. Parahitiyawa, Y. H. Samaranayake, L. P. Samaranayake et al., "Interspecies variation in Candida biofilm formation studied using the Calgary biofilm device," Acta Pathologica, 
Microbiologica et Immunologica Scandinavica, vol. 114, no. 4, pp. 298-306, 2006.

[42] A. Srinivasan, P. Uppuluri, J. Lopez-Ribot, and A. K. Ramasubramanian, "Development of a high-throughput Candida albicans biofilm chip," PLoS ONE, vol. 6, no. 4, Article ID e19036, 2011.

[43] K. Honraet, E. Goetghebeur, and H. J. Nelis, "Comparison of three assays for the quantification of Candida biomass in suspension and CDC reactor grown biofilms," Journal of Microbiological Methods, vol. 63, no. 3, pp. 287-295, 2005.

[44] S. García-Sánchez, S. Aubert, I. Iraqui, G. Janbon, J. M. Ghigo, and C. D'Enfert, "Candida albicans biofilms: a developmental state associated with specific and stable gene expression patterns," Eukaryotic Cell, vol. 3, no. 2, pp. 536545, 2004.

[45] G. Ramage, B. L. Wickes, and J. L. López-Ribot, "A seed and feed model for the formation of Candida albicans biofilms under flow conditions using an improved modified Robbins device," Revista Iberoamericana de Micologia, vol. 25, no. 1, pp. 37-40, 2008.

[46] P. Uppuluri, A. K. Chaturvedi, and J. L. Lopez-Ribot, "Design of a simple model of Candida albicans biofilms formed under conditions of flow: development, architecture, and drug resistance," Mycopathologia, vol. 168, no. 3, pp. 101$109,2009$.

[47] P. K. Mukherjee, D. V. Chand, J. Chandra, J. M. Anderson, and M. A. Ghannoum, "Shear stress modulates the thickness and architecture of Candida albicans biofilms in a phasedependent manner," Mycoses, vol. 52, no. 5, pp. 440-446, 2009.

[48] T. Bergendal and G. Isacsson, "A combined clinical, mycological and histological study of denture stomatitis," Acta Odontologica Scandinavica, vol. 41, no. 1, pp. 33-44, 1983.

[49] E. Agwu, J. C. Ihongbe, B. A. McManus, G. P. Moran, D. C. Coleman, and D. J. Sullivan, "Distribution of yeast speciesassociated with oral lesions in HIV-infected patients in Southwest Uganda," Medical Mycology. In press.

[50] D. Estivill, A. Arias, A. Torres-Lana, A. J. Carrillo-Muñoz, and M. P. Arévalo, "Biofilm formation by five species of Candida on three clinical materials," Journal of Microbiological Methods, vol. 86, no. 2, pp. 238-242, 2011.

[51] D. M. MacCallum, L. Castillo, K. Nather et al., "Property differences among the four major Candida albicans strain clades," Eukaryotic Cell, vol. 8, no. 3, pp. 373-387, 2009.

[52] F. C. Odds, "Molecular phylogenetics and epidemiology of Candida albicans," Future Microbiology, vol. 5, no. 1, pp. 6779, 2010.

[53] A. Tavanti, A. D. Davidson, N. A. R. Gow, M. C. J. Maiden, and F. C. Odds, "Candida orthopsilosis and Candida metapsilosis spp. nov. to replace Candida parapsilosis groups II and III," Journal of Clinical Microbiology, vol. 43, no. 1, pp. 284-292, 2005.

[54] J. W. Song, J. H. Shin, D. H. Shin et al., "Differences in biofilm production by three genotypes of Candida parapsilosis from clinical sources," Medical Mycology, vol. 43, no. 7, pp. 657661, 2005.

[55] A. Tavanti, L. A. M. Hensgens, E. Ghelardi, M. Campa, and S. Senesi, "Genotyping of Candida orthopsilosis clinical isolates by amplification fragment length polymorphism reveals genetic diversity among independent isolates and strain maintenance within patients," Journal of Clinical Microbiology, vol. 45, no. 5, pp. 1455-1462, 2007.
[56] A. Tavanti, L. A. Hensgens, S. Mogavero, L. Majoros, S. Senesi, and M. Campa, "Genotypic and phenotypic properties of Candida parapsilosis sensu strictu strains isolated from different geographic regions and body sites," $B M C$ Microbiology, vol. 10, article 203, 2010.

[57] Y. Imamura, J. Chandra, P. K. Mukherjee et al., "Fusarium and Candida albicans biofilms on soft contact lenses: model development, influence of lens type, and susceptibility to lens care solutions," Antimicrobial Agents and Chemotherapy, vol. 52, no. 1, pp. 171-182, 2008.

[58] J. Chandra, D. M. Kuhn, P. K. Mukherjee, L. L. Hoyer, T. McCormick, and M. A. Ghannoum, "Biofilm formation by the fungal pathogen Candida albicans: development, architecture, and drug resistance," Journal of Bacteriology, vol. 183, no. 18, pp. 5385-5394, 2001.

[59] P. Uppuluri, H. Dinakaran, D. P. Thomas, A. K. Chaturvedi, and J. L. Lopez-Ribot, "Characteristics of Candida albicans biofilms grown in a synthetic urine medium," Journal of Clinical Microbiology, vol. 47, no. 12, pp. 4078-4083, 2009.

[60] N. Jain, R. Kohli, E. Cook, P. Gialanella, T. Chang, and B. C. Fries, "Biofilm formation by and antifungal susceptibility of Candida isolates from urine," Applied and Environmental Microbiology, vol. 73, no. 6, pp. 1697-1703, 2007.

[61] M. Negri, S. Silva, M. Henriques, J. Azeredo, T. Svidzinski, and R. Oliveira, "Candida tropicalis biofilms: artificial urine, urinary catheters and flow model," Medical Mycology, vol. 49, no. 7, pp. 739-747, 2011.

[62] H. J. Busscher and H. C. van der Mei, "Microbial adhesion in flow displacement systems," Clinical Microbiology Reviews, vol. 19, no. 1, pp. 127-141, 2006.

[63] M. R. Benoit, C. G. Conant, C. Ionescu-Zanetti, M. Schwartz, and A. Matin, "New device for high-throughput viability screening of flow biofilms," Applied and Environmental Microbiology, vol. 76, no. 13, pp. 4136-4142, 2010.

[64] M. K. Schinabeck, L. A. Long, M. A. Hossain et al., "Rabbit model of Candida albicans biofilm infection: 1liposomal amphotericin B antifungal lock therapy," Antimicrobial Agents and Chemotherapy, vol. 48, no. 5, pp. 1727-1732, 2004.

[65] A. L. Lazzell, A. K. Chaturvedi, C. G. Pierce, D. Prasad, P. Uppuluri, and J. L. Lopez-Ribot, "Treatment and prevention of Candida albicans biofilms with caspofungin in a novel central venous catheter murine model of candidiasis," Journal of Antimicrobial Chemotherapy, vol. 64, no. 3, pp. 567-570, 2009.

[66] X. Wang and B. C. Fries, "A murine model for catheterassociated Candiduria," Journal of Medical Microbiology, vol. 60, no. 10, pp. 1523-1529, 2011.

[67] J. E. Nett, K. Marchillo, C. A. Spiegel, and D. R. Andes, "Development and validation of an in vivoCandida albicans biofilm denture model," Infection and Immunity, vol. 78, no. 9, pp. 3650-3659, 2010.

[68] H. Lee, A. Yu, C. C. Johnson, E. A. Lilly, M. C. Noverr, and P. L. Fidel, "Fabrication of a multi-applicable removable intraoral denture system for rodent research," Journal of Oral Rehabilitation, vol. 38, no. 9, pp. 686-690, 2011.

[69] M. M. Harriott, E. A. Lilly, T. E. Rodriguez, P. L. Fidel Jr., and M. C. Noverr, "Candida albicans forms biofilms on the vaginal mucosa," Microbiology, vol. 156, no. 12, pp. 36353644, 2010.

[70] T. Coenye and H. J. Nelis, "In vitro and in vivo model systems to study microbial biofilm formation," Journal of Microbiological Methods, vol. 83, no. 2, pp. 89-105, 2010. 
[71] L. R. Martinez, M. R. Mihu, M. Tar et al., "Demonstration of antibiofilm and antifungal efficacy of chitosan against candidal biofilms, using an in vivo central venous catheter model," Journal of Infectious Diseases, vol. 201, no. 9, pp. 1436-1440, 2010.

[72] S. Kucharíková, H. Tournu, M. Holtappels, P. Van Dijck, and K. Lagrou, "In vivo efficacy of anidulafungin against mature Candida albicans biofilms in a novel rat model of catheter-associated candidiasis," Antimicrobial Agents and Chemotherapy, vol. 54, no. 10, pp. 4474-4475, 2010.

[73] D. M. Kuhn, T. George, J. Chandra, P. K. Mukherjee, and M. A. Ghannoum, "Antifungal susceptibility of Candida biofilms: unique efficacy of amphotericin B lipid formulations and echinocandins," Antimicrobial Agents and Chemotherapy, vol. 46, no. 6, pp. 1773-1780, 2002.

[74] L. Hall-Stoodley and P. Stoodley, "Evolving concepts in biofilm infections," Cellular Microbiology, vol. 11, no. 7, pp. 1034-1043, 2009.

[75] C. Hannig and M. Hannig, "The oral cavity-a key system to understand substratum-dependent bioadhesion on solid surfaces in man," Clinical Oral Investigations, vol. 13, no. 2, pp. 123-139, 2009.

[76] D. K. Morales and D. A. Hogan, "Candida albicans interactions with bacteria in the context of human health and disease," PLoS pathogens, vol. 6, no. 4, Article ID e1000886, 2010.

[77] V. Holá, F. Ruzicka, and M. Horka, "Microbial diversity in biofilm infections of the urinary tract with the use of sonication techniques," FEMS Immunology and Medical Microbiology, vol. 59, no. 3, pp. 525-528, 2010.

[78] Z. M. Thein, C. J. Seneviratne, Y. H. Samaranayake, and L. P. Samaranayake, "Community lifestyle of Candida in mixed biofilms: a mini review," Mycoses, vol. 52, no. 6, pp. 467-475, 2009.

[79] M. E. Shirtliff, B. M. Peters, and M. A. Jabra-Rizk, "Crosskingdom interactions: Candida albicans and bacteria," FEMS Microbiology Letters, vol. 299, no. 1, pp. 1-8, 2009.

[80] B. M. Peters, M. A. Jabra-Rizk, M. A. Scheper, J. G. Leid, J. W. Costerton, and M. E. Shirtliff, "Microbial interactions and differential protein expression in Staphylococcus aureus -Candida albicans dual-species biofilms," FEMS Immunology and Medical Microbiology, vol. 59, no. 3, pp. 493-503, 2010.

[81] Z. M. Thein, Y. H. Samaranayake, and L. P. Samaranayake, "Effect of oral bacteria on growth and survival of Candida albicans biofilms," Archives of Oral Biology, vol. 51, no. 8, pp. 672-680, 2006.

[82] M. A. El-Azizi, S. E. Starks, and N. Khardori, "Interactions of Candida albicans with other Candida spp. and bacteria in the biofilms," Journal of Applied Microbiology, vol. 96, no. 5, pp. 1067-1073, 2004.

[83] J. M. Ten Cate, F. M. Klis, T. Pereira-Cenci, W. Crielaard, and P. W. J. De Groot, "Molecular and cellular mechanisms that lead to Candida biofilm formation," Journal of Dental Research, vol. 88, no. 2, pp. 105-115, 2009.

[84] M. M. Harriott and M. C. Noverr, "Candida albicans and Staphylococcus aureus form polymicrobial biofilms: effects on antimicrobial resistance," Antimicrobial Agents and Chemotherapy, vol. 53, no. 9, pp. 3914-3922, 2009.

[85] A. H. Nobbs, M. Margaret Vickerman, and H. F. Jenkinson, "Heterologous expression of Candida albicans cell wall-associated adhesins in Saccharomyces cerevisiae reveals differential specificities in adherence and biofilm formation and in binding oral Streptococcus gordonii," Eukaryotic Cell, vol. 9, no. 10, pp. 1622-1634, 2010.
[86] S. A. Klotz, N. K. Gaur, R. De Armond et al., "Candida albicans Als proteins mediate aggregation with bacteria and yeasts," Medical Mycology, vol. 45, no. 4, pp. 363-370, 2007.

[87] R. J. Silverman, A. H. Nobbs, M. M. Vickerman, M. E. Barbour, and H. F. Jenkinson, "Interaction of Candida albicans cell wall Als3 Protein with Streptococcus gordonii $\mathrm{SspB}$ adhesin promotes development of mixed-species communities," Infection and Immunity, vol. 78, no. 11, pp. 46444652, 2010.

[88] Y. Liu and S. G. Filler, "Candida albicans Als3, a multifunctional adhesin and invasin," Eukaryotic Cell, vol. 10, no. 2, pp. 168-173, 2011.

[89] L. M. Jarosz, D. M. Deng, H. C. van der Mei, W. Crielaard, and B. P. Krom, "Streptococcus mutans competencestimulating peptide inhibits Candida albicans hypha formation," Eukaryotic Cell, vol. 8, no. 11, pp. 1658-1664, 2009.

[90] R. Vílchez, A. Lemme, B. Ballhausen et al., "Streptococcus mutans inhibits Candida albicans hyphal formation by the fatty acid signaling molecule trans-2-decenoic acid (SDSF)," ChemBioChem, vol. 11, no. 11, pp. 1552-1562, 2010.

[91] C. V. Bamford, A. D’Mello, A. H. Nobbs, L. C. Dutton, M. M. Vickerman, and H. F. Jenkinson, "Streptococcus gordonii modulates Candida albicans biofilm formation through intergeneric communication," Infection and Immunity, vol. 77, no. 9, pp. 3696-3704, 2009.

[92] D. A. Hogan and R. Kolter, "Pseudomonas-Candida interactions: an ecological role for virulence factors," Science, vol. 296, no. 5576, pp. 2229-2232, 2002.

[93] H. M. H. N. Bandara, J. Y. Y. Yau, R. M. Watt, L. J. Jin, and L. P. Samaranayake, "Pseudomonas aeruginosa inhibits in-vitro Candida biofilm development," BMC Microbiology, p. 125, 2010.

[94] H. M. H. N. Bandara, J. Y. Y. Yau, R. M. Watt, L. J. Jin, and L. P. Samaranayake, "Escherichia coli and its lipopolysaccharide modulate in vitro Candida biofilm formation," Journal of Medical Microbiology, vol. 58, no. 12, pp. 1623-1631, 2009.

[95] R. G. Nair, S. Anil, and L. P. Samaranayake, "The effect of oral bacteria on Candida albicans germ-tube formation," Acta Pathologica, Microbiologica et Immunologica Scandinavica, vol. 109, no. 2, pp. 147-154, 2001.

[96] D. W. Denning and W. W. Hope, "Therapy for fungal diseases: opportunities and priorities," Trends in Microbiology, vol. 18, no. 5, pp. 195-204, 2010.

[97] M. A. Jabra-Rizk, W. A. Falkler, and T. F. Meiller, "Fungal biofilms and drug resistance," Emerging Infectious Diseases, vol. 10, no. 1, pp. 14-19, 2004.

[98] K. Lewis, "Multidrug tolerance of biofilms and persister cells," Current Topics in Microbiology and Immunology, vol. 322, pp. 107-131, 2008.

[99] E. M. Kojic and R. O. Darouiche, "Candida infections of medical devices," Clinical Microbiology Reviews, vol. 17, no. 2, pp. 255-267, 2004.

[100] R. Cauda, "Candidaemia in patients with an inserted medical device,” Drugs, vol. 69, supplement 1, pp. 33-38, 2009.

[101] M. Christner, G. C. Franke, N. N. Schommer et al., "The giant extracellular matrix-binding protein of Staphylococcus epidermidis mediates biofilm accumulation and attachment to fibronectin," Molecular Microbiology, vol. 75, no. 1, pp. 187-207, 2010.

[102] L. A. Mermel, M. Allon, E. Bouza et al., "Clinical practice guidelines for the diagnosis and management of intravascular catheter-related infection: 2009 update by the infectious diseases society of America," Clinical Infectious Diseases, vol. 49, no. 1, pp. 1-45, 2009. 
[103] J. Carratalà, "The antibiotic-lock technique for therapy of "highly needed" infected catheters," Clinical Microbiology and Infection, vol. 8, no. 5, pp. 282-289, 2002.

[104] P. Viale, N. Petrosillo, L. Signorini, M. Puoti, and G. Carosi, "Should lock therapy always be avoided for central venous catheter-associated fungal bloodstream infections?" Clinical Infectious Diseases, vol. 33, no. 11, pp. 1947-1948, 2001.

[105] A. Angel-Moreno, M. Boronat, M. Bolaños, A. Carrillo, S. González, and J. L. Pérez Arellano, "Candida glabrata fungemia cured by antibiotic-lock therapy: case report and short review," Journal of Infection, vol. 51, no. 3, pp. e85-e87, 2005.

[106] R. M. Donlan, "Biofilms on central venous catheters: is eradication possible?" Current Topics in Microbiology and Immunology, vol. 322, pp. 133-161, 2008.

[107] E. Cateau, J. M. Berjeaud, and C. Imbert, "Possible role of azole and echinocandin lock solutions in the control of Candida biofilms associated with silicone," International Journal of Antimicrobial Agents, vol. 37, no. 4, pp. 380-384, 2011.

[108] P. K. Mukherjee, L. Long, H. G. Kim, and M. A. Ghannoum, "Amphotericin B lipid complex is efficacious in the treatment of Candida albicans biofilms using a model of catheter-associated Candida biofilms," International Journal of Antimicrobial Agents, vol. 33, no. 2, pp. 149-153, 2009.

[109] M. Venkatesh, L. Rong, I. Raad, and J. Versalovic, "Novel synergistic antibiofilm combinations for salvage of infected catheters," Journal of Medical Microbiology, vol. 58, no. 7, pp. 936-944, 2009.

[110] M. H. Miceli, S. M. Bernardo, and S. A. Lee, "In vitro analyses of the combination of high-dose doxycycline and antifungal agents against Candida albicans biofilms," International Journal of Antimicrobial Agents, vol. 34, no. 4, pp. 326-332, 2009.

[111] T. S. N. Ku, S. K. A. Palanisamy, and S. A. Lee, "Susceptibility of Candida albicans biofilms to azithromycin, tigecycline and vancomycin and the interaction between tigecycline and antifungals," International Journal of Antimicrobial Agents, vol. 36, no. 5, pp. 441-446, 2010.

[112] J. Edgeworth, "Intravascular catheter infections," Journal of Hospital Infection, vol. 73, no. 4, pp. 323-330, 2009.

[113] J. C. Hockenhull, K. M. Dwan, G. W. Smith et al., "The clinical effectiveness of central venous catheters treated with antiinfective agents in preventing catheter-related bloodstream infections: a systematic review," Critical Care Medicine, vol. 37, no. 2, pp. 702-712, 2009.

[114] M. Quirynen and C. M. Bollen, "The influence of surface roughness and surface-free energy on supra- and subgingival plaque formation in man. A review of the literature," Journal of Clinical Periodontology, vol. 22, no. 1, pp. 1-14, 1995.

[115] W. Teughels, N. Van Assche, I. Sliepen, and M. Quirynen, "Effect of material characteristics and/or surface topography on biofilm development," Clinical Oral Implants Research, vol. 17, no. 2, pp. 68-81, 2006.

[116] D. R. Radford, S. P. Sweet, S. J. Challacombe, and J. D. Walter, "Adherence of Candida albicans to denture-base materials with different surface finishes," Journal of Dentistry, vol. 26, no. 7, pp. 577-583, 1998.

[117] Y. Xiong and Y. Liu, "Biological control of microbial attachment: a promising alternative for mitigating membrane biofouling," Applied Microbiology and Biotechnology, vol. 86, no. 3, pp. 825-837, 2010.

[118] K. Bruellhoff, J. Fiedler, M. Möller, J. Groll, and R. E. Brenner, "Surface coating strategies to prevent biofilm formation on implant surfaces," International Journal of Artificial Organs, vol. 33, no. 9, pp. 646-653, 2010.

[119] H. J. Busscher, M. Rinastiti, W. Siswomihardjo, and H. C. van der Mei, "Biofilm formation on dental restorative and implant materials," Journal of Dental Research, vol. 89, no. 7, pp. 657-665, 2010.

[120] J. M. Anderson, A. Rodriguez, and D. T. Chang, "Foreign body reaction to biomaterials," Seminars in Immunology, vol. 20, no. 2, pp. 86-100, 2008.

[121] C. A. B. Nava-Ortiz, G. Burillo, A. Concheiro et al., "Cyclodextrin-functionalized biomaterials loaded with miconazole prevent Candida albicans biofilm formation in vitro," Acta Biomaterialia, vol. 6, no. 4, pp. 1398-1404, 2010.

[122] A. Contreras-García, E. Bucioa, G. Brackmanc, T. Coenyec, A. Concheirob, and C. Alvarez-Lorenzob, "Biofilm inhibition and drug-eluting properties of novel DMAEMA-modified polyethylene and silicone rubber surfaces," Biofouling, vol. 27, no. 2, pp. 123-135, 2011.

[123] J. Chandra, J. D. Patel, J. Li et al., "Modification of surface properties of biomaterials influences the ability of Candida albicans to form biofilms," Applied and Environmental Microbiology, vol. 71, no. 12, pp. 8795-8801, 2005.

[124] K. de Prijck, N. de Smet, T. Coenye, E. Schacht, and H. J. Nelis, "Prevention of Candida albicans biofilm formation by covalently bound dimethylaminoethylmethacrylate and polyethylenimine," Mycopathologia, vol. 170, no. 4, pp. 213221, 2010.

[125] K. De Prijck, N. De Smet, M. Rymarczyk-Machal et al., "Candida albicans biofilm formation on peptide functionalized polydimethylsiloxane," Biofouling, vol. 26, no. 3, pp. 269-275, 2010.

[126] S. Redding, B. Bhatt, H. R. Rawls, G. Siegel, K. Scott, and J. Lopez-Ribot, "Inhibition of Candida albicans biofilm formation on denture material," Oral Surgery, Oral Medicine, Oral Pathology, Oral Radiology and Endodontology, vol. 107, no. 5, pp. 669-672, 2009.

[127] A. J. Karlsson, R. M. Flessner, S. H. Gellman, D. M. Lynn, and S. P. Palecek, "Polyelectrolyte multilayers fabricated from antifungal $\beta$-peptides: design of surfaces that exhibit antifungal activity against Candida albicans," Biomacromolecules, vol. 11, no. 9, pp. 2321-2328, 2010.

[128] A. Zumbuehl, L. Ferreira, D. Kuhn et al., "Antifungal hydrogels," Proceedings of the National Academy of Sciences of the United States of America, vol. 104, no. 32, pp. 1299412998, 2007.

[129] S. P. Hudson, R. Langer, G. R. Fink, and D. S. Kohane, "Injectable in situ cross-linking hydrogels for local antifungal therapy," Biomaterials, vol. 31, no. 6, pp. 1444-1452, 2010.

[130] B. J. Privett, S. T. Nutz, and M. H. Schoenfisch, "Efficacy of surface-generated nitric oxide against Candida albicans adhesion and biofilm formation," Biofouling, vol. 26, no. 8, pp. 973-983, 2010.

[131] R. P. Carlson, R. Taffs, W. M. Davison, and P. S. Stewart, "Anti-biofilm properties of chitosan-coated surfaces," Journal of Biomaterials Science, Polymer Edition, vol. 19, no. 8, pp. 1035-1046, 2008.

[132] C. R. Pusateri, E. A. Monaco, and M. Edgerton, "Sensitivity of Candida albicans biofilm cells grown on denture acrylic to antifungal proteins and chlorhexidine," Archives of Oral Biology, vol. 54, no. 6, pp. 588-594, 2009.

[133] A. Matejuk, Q. Leng, M. D. Begum et al., "Peptide-based antifungal therapies against emerging infections," Drugs of the Future, vol. 35, no. 3, pp. 197-217, 2010. 
[134] P.-W. Tsai, C.-Y. Yang, H.-T. Chang, and C.-Y. Lan, "Human antimicrobial peptide LL-37 inhibits adhesion of Candida albicans by interacting with yeast cell-wall carbohydrates," PLoS ONE, vol. 6, no. 3, Article ID e17755, 2011.

[135] S. L. Avon, J. P. Goulet, and N. Deslauriers, "Removable acrylic resin disk as a sampling system for the study of denture biofilms in vivo," Journal of Prosthetic Dentistry, vol. 97, no. 1, pp. 32-38, 2007.

[136] G. Ramage, S. P. Saville, B. L. Wickes, and J. L. LópezRibot, "Inhibition of Candida albicans biofilm formation by farnesol, a quorum-sensing molecule," Applied and Environmental Microbiology, vol. 68, no. 11, pp. 5459-5463, 2002.

[137] M. A. S. Alem, M. D. Y. Oteef, T. H. Flowers, and L. J. Douglas, "Production of tyrosol by Candida albicans biofilms and its role in quorum sensing and biofilm development," Eukaryotic Cell, vol. 5, no. 10, pp. 1770-1779, 2006.

[138] D. H.M.L.P. Navarathna, J. M. Hornby, N. Hoerrmann, A. M. Parkhurst, G. E. Duhamel, and K. W. Nickerson, "Enhanced pathogenicity of Candida albicans pre-treated with subinhibitory concentrations of fluconazole in a mouse model of disseminated candidiasis," Journal of Antimicrobial Chemotherapy, vol. 56, no. 6, pp. 1156-1159, 2005.

[139] D. H. M. L. P. Navarathna, J. M. Hornby, N. Krishnan, A. Parkhurst, G. E. Duhamel, and K. W. Nickerson, "Effect of farnesol on a mouse model of systemic candidiasis, determined by use of a DPP3 knockout mutant of Candida albicans," Infection and Immunity, vol. 75, no. 4, pp. 16091618, 2007.

[140] D. H. M. L. P. Navarathna, K. W. Nickerson, G. E. Duhamel, T. R. Jerrels, and T. M. Petro, "Exogenous farnesol interferes with the normal progression of cytokine expression during candidiasis in a mouse model," Infection and Immunity, vol. 75, no. 8, pp. 4006-4011, 2007.

[141] R. Shchepin, D. H.M.L.P. Navarathna, R. Dumitru, S. Lippold, K. W. Nickerson, and P. H. Dussault, "Influence of heterocyclic and oxime-containing farnesol analogs on quorum sensing and pathogenicity in Candida albicans," Bioorganic and Medicinal Chemistry, vol. 16, no. 4, pp. 18421848, 2008.

[142] D. A. Hogan, A. Vik, and R. Kolter, "A Pseudomonas aeruginosa quorum-sensing molecule influences Candida albicans morphology," Molecular Microbiology, vol. 54, no. 5, pp. 1212-1223, 2004.

[143] D. K. Morales, N. J. Jacobs, S. Rajamani, M. Krishnamurthy, J. R. Cubillos-Ruiz, and D. A. Hogan, "Antifungal mechanisms by which a novel Pseudomonas aeruginosa phenazine toxin kills Candida albicans in biofilms," Molecular Microbiology, vol. 78, no. 6, pp. 1379-1392, 2010.

[144] J. Valle, S. Da Re, M. Henry et al., "Broad-spectrum biofilm inhibition by a secreted bacterial polysaccharide," Proceedings of the National Academy of Sciences of the United States of America, vol. 103, no. 33, pp. 12558-12563, 2006.

[145] O. Rendueles, L. Travier, P. Latour-Lambert et al., "Screening of Escherichia coli species biodiversity reveals new biofilmassociated antiadhesion polysaccharides," mBio, vol. 2, no. 3, Article ID e00043-11, 2011.

[146] H. M. H. N. Bandara, O. L. T. Lam, R. M. Watt, L. J. Jin, and L. P. Samaranayake, "Bacterial lipopolysaccharides variably modulate in vitro biofilm formation of Candida species," Journal of Medical Microbiology, vol. 59, no. 10, pp. 12251234, 2010.

[147] J. Njoroge and V. Sperandio, "Jamming bacterial communication: new approaches for the treatment of infectious diseases," EMBO Molecular Medicine, vol. 1, no. 4, pp. 201210, 2009.

[148] A. J. Macedo and W. R. Abraham, "Can infectious biofilm be controlled by blocking bacterial communication?" Medicinal Chemistry, vol. 5, no. 6, pp. 517-528, 2009.

[149] V. Lazar, "Quorum sensing in biofilms-how to destroy the bacterial citadels ortheir cohesion/power?" Anaerobe. In press.

[150] J. W.M. Van Der Meer, F. L. Van De Veerdonk, L. A.B. Joosten, B.-J. Kullberg, and M. G. Netea, "Severe Candida spp. infections: new insights into natural immunity," International Journal of Antimicrobial Agents, vol. 36, supplement 2, pp. S58-S62, 2010.

[151] C. Bourgeois, O. Majer, I. E. Frohner, L. Tierney, and K. Kuchler, "Fungal attacks on mammalian hosts: pathogen elimination requires sensing and tasting," Current Opinion in Microbiology, vol. 13, no. 4, pp. 401-408, 2010.

[152] K. Seider, A. Heyken, A. Lüttich, P. Miramón, and B. Hube, "Interaction of pathogenic yeasts with phagocytes: survival, persistence and escape," Current Opinion in Microbiology, vol. 13, no. 4, pp. 392-400, 2010.

[153] B. J. Kullberg, A. M. L. Oude Lashof, and M. G. Netea, "Design of efficacy trials of cytokines in combination with antifungal drugs," Clinical Infectious Diseases, vol. 39, no. 4, pp. S218-S223, 2004.

[154] K. L. Wozniak, G. Palmer, R. Kutner, and P. L. Fidel Jr., "Immunotherapeutic approaches to enhance protective immunity against Candida vaginitis," Medical Mycology, vol. 43, no. 7, pp. 589-601, 2005.

[155] J. Chandra, T. S. McCormick, Y. Imamura, P. K. Mukherjee, and M. A. Ghannoum, "Interaction of Candida albicans with adherent human peripheral blood mononuclear cells increases C. albicans biofilm formation and results in differential expression of pro- and anti-inflammatory cytokines," Infection and Immunity, vol. 75, no. 5, pp. 2612-2620, 2007.

[156] A. Katragkou, M. J. Kruhlak, M. Simitsopoulou et al., "Interactions between human phagocytes and Candida albicans biofilms alone and in combination with antifungal agents," Journal of Infectious Diseases, vol. 201, no. 12, pp. 1941-1949, 2010.

[157] A. Katragkou, A. Chatzimoschou, M. Simitsopoulou, E. Georgiadou, and E. Roilides, "Additive antifungal activity of anidulafungin and human neutrophils against Candida parapsilosis biofilms," Journal of Antimicrobial Chemotherapy, vol. 66, no. 3, pp. 588-591, 2011.

[158] R. T. Wheeler and G. R. Fink, "A drug-sensitive genetic network masks fungi from the immune system," PLoS Pathogens, vol. 2, no. 4, article e35, pp. 328-339, 2006.

[159] T. F. Meiller, B. Hube, L. Schild et al., "A novel immune evasion strategy of Candida albicans: proteolytic cleavage of a salivary antimicrobial peptide," PLoS ONE, vol. 4, no. 4, Article ID e5039, 2009.

[160] S. Luo, S. Poltermann, A. Kunert, S. Rupp, and P. F. Zipfel, "Immune evasion of the human pathogenic yeast Candida albicans: pra1 is a Factor H, FHL-1 and plasminogen binding surface protein," Molecular Immunology, vol. 47, no. 2-3, pp. 541-550, 2009.

[161] K. Gropp, L. Schild, S. Schindler, B. Hube, P. F. Zipfel, and C. Skerka, "The yeast Candida albicans evades human complement attack by secretion of aspartic proteases," Molecular Immunology, vol. 47, no. 2-3, pp. 465-475, 2009.

[162] D. S. Perlin, "Current perspectives on echinocandin class drugs," Future Microbiology, vol. 6, no. 4, pp. 441-457, 2011. 
[163] M. Galán-Díez, D. M. Arana, D. Serrano-Gómez et al., "Candida albicans $\beta$-glucan exposure is controlled by the fungal CEK1-mediated mitogen-activated protein kinase pathway that modulates immune responses triggered through dectin1," Infection and Immunity, vol. 78, no. 4, pp. 1426-1436, 2010.

[164] D. M. Reid, N. A. Gow, and G. D. Brown, "Pattern recognition: recent insights from Dectin-1," Current Opinion in Immunology, vol. 21, no. 1, pp. 30-37, 2009.

[165] J. Nett, L. Lincoln, K. Marchillo, and D. Andes, " $\beta-1,3$ glucan as a test for central venous catheter biofilm infection," Journal of Infectious Diseases, vol. 195, no. 11, pp. 1705-1712, 2007.

[166] A. J. Jesaitis, M. J. Franklin, D. Berglund et al., "Compromised host defense on Pseudomonas aeruginosa biofilms: characterization of neutrophil and biofilm interactions," Journal of Immunology, vol. 171, no. 8, pp. 4329-4339, 2003.

[167] G. Luo, A. S. Ibrahim, B. Spellberg, C. J. Nobile, A. P. Mitchell, and Y. Fu, "Candida albicans Hyrlp confers resistance to neutrophil killing and is a potential vaccine target," Journal of Infectious Diseases, vol. 201, no. 11, pp. 1718-1728, 2010.

[168] F. L. van de Veerdonk, M. G. Netea, L. A. Joosten, J. W.M. van der Meer, and B. J. Kullberg, "Novel strategies for the preventionand treatment of Candida infections: the potential of immunotherapy," FEMS Microbiology Reviews, vol. 34, no. 6, pp. 1063-1075, 2010.

[169] H. Bujdáková, E. Paulovičová, L. Paulovičová, and Z. Šimová, "Participation of the Candida albicans surface antigen in adhesion, the first phase of biofilm development," FEMS Immunology and Medical Microbiology, vol. 59, no. 3, pp. 485-492, 2010.

[170] T. Fujibayashi, M. Nakamura, A. Tominaga et al., "Effects of IgY against Candida albicans and Candida spp. adherence and biofilm formation," Japanese Journal of Infectious Diseases, vol. 62, no. 5, pp. 337-342, 2009.

[171] A. Dürig, I. Kouskoumvekaki, R. M. Vejborg, and P. Klemm, "Chemoinformatics-assisted development of new anti-biofilm compounds," Applied Microbiology and Biotechnology, vol. 87, no. 1, pp. 309-317, 2010. 

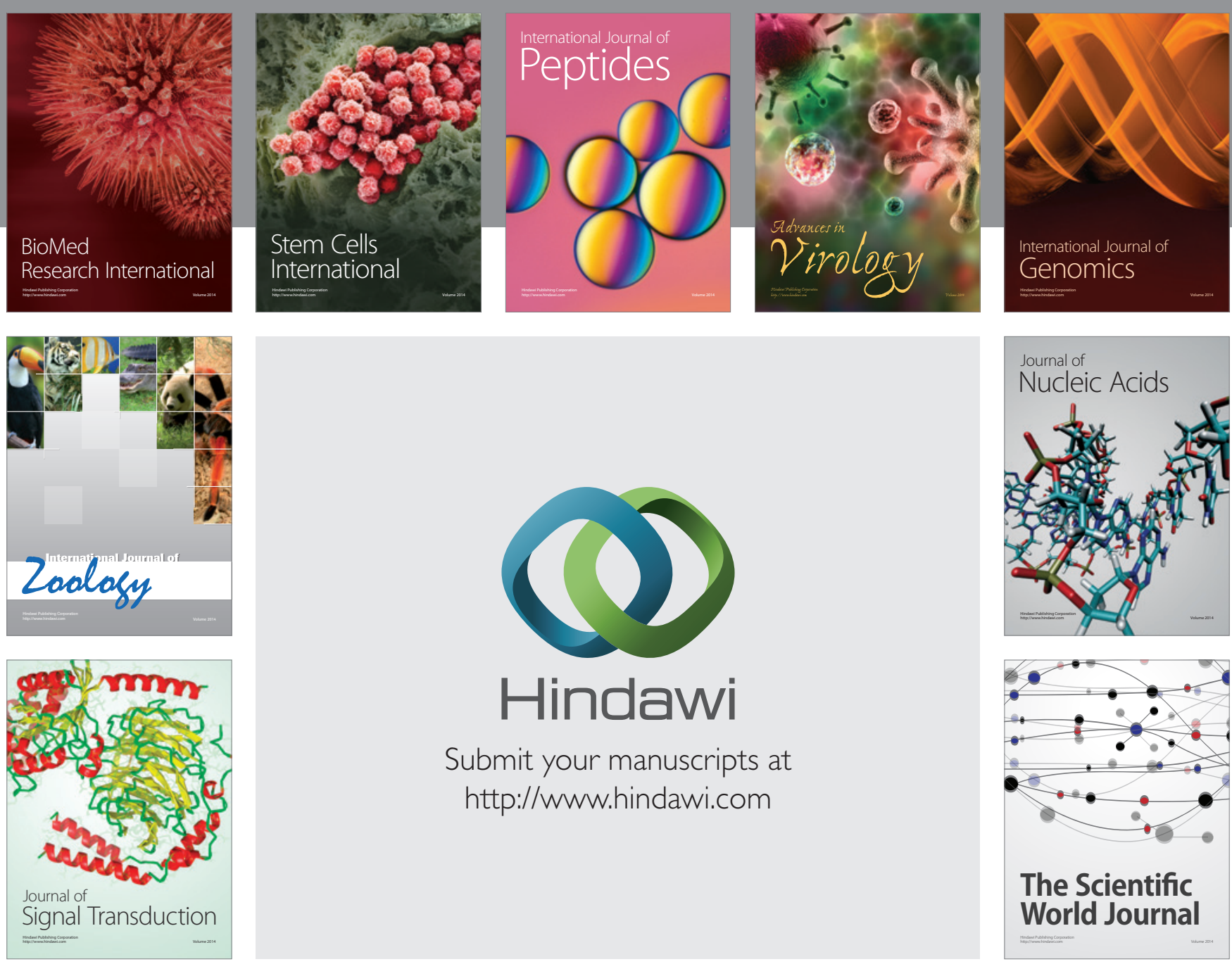

Submit your manuscripts at

http://www.hindawi.com
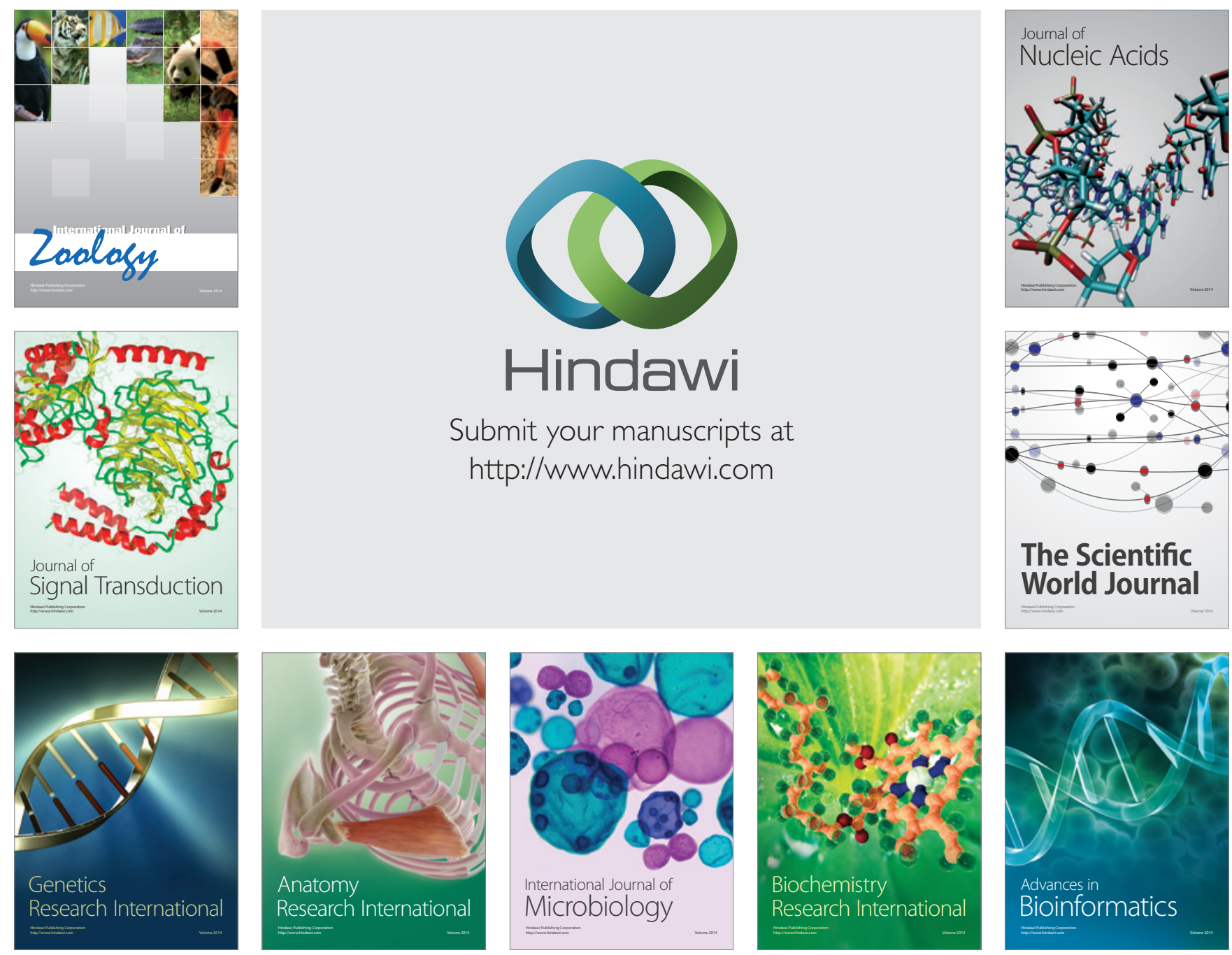

The Scientific World Journal
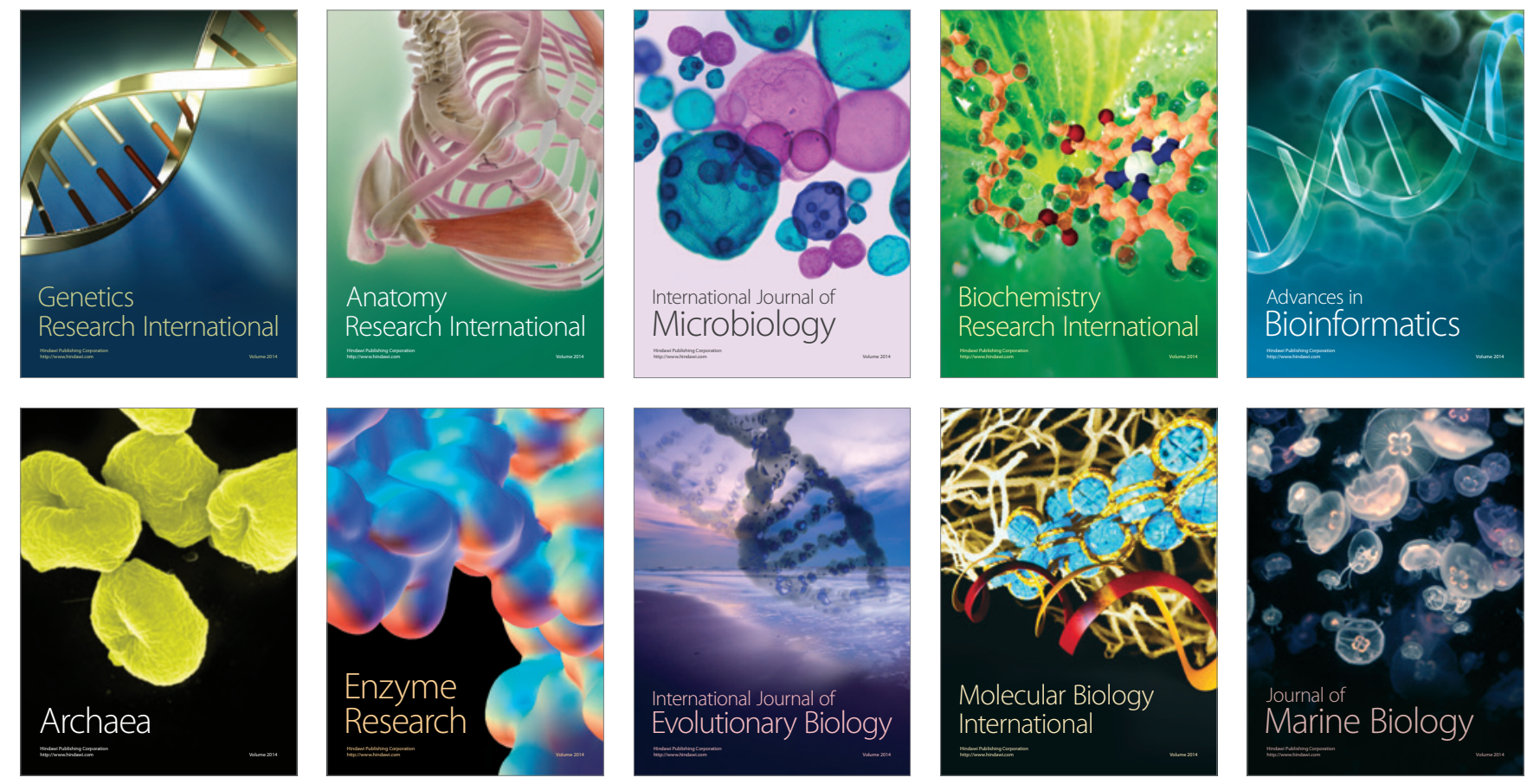